\title{
Allozyme and DNA sequence comparisons of nine species of Encephalartos (Zamiaceae)
}

\author{
Herman van der Bank ${ }^{\mathrm{a}, *}$, Michael Wink ${ }^{\mathrm{b}}$, Piet Vorster ${ }^{\mathrm{c}}$, \\ Jens Treutlein ${ }^{\mathrm{b}}$, Louise Brand ${ }^{\mathrm{a}}$, Michelle van der Bank ${ }^{\mathrm{a}}$, \\ Johan Hurter ${ }^{\mathrm{d}}$
}

a Department of Zoology, Department of Botany, Rand Afrikaans University, PO Box 524, Auckland Park 2006, South Africa

${ }^{\mathrm{b}}$ Universität Heidelberg, Institut für Pharmazeutische Biologie, Im Neuenheimer Feld 364 , 69120 Heidelberg, Germany

${ }^{\mathrm{c}}$ Department of Botany, University of Stellenbosch, Private Bag X1, 7602 Matieland, South Africa

${ }^{\mathrm{d}}$ Lowveld National Botanical Garden, PO Box 1024, Nelspruit 1200, South Africa

Received 21 February 2000; accepted 10 April 2000

\begin{abstract}
Phylogenetic relationships between Encephalartos altensteinii Lehmann, E. arenarius R.A. Dyer, E. horridus (Jacquin) Lehmann, E. latifrons Lehmann, E. lehmannii Lehmann, E. longifolius (Jacquin) Lehmann, E. princeps R.A. Dyer and E. trispinosus (Hooker) R.A. Dyer were studied, using E. ferox Bertoloni f. as outgroup. Three continuous and one discontinuous buffer systems were used and gene products of 14 enzyme coding loci were examined by horizontal starch gel-electrophoresis. Genetic variation was studied in a cultivated population of E. lehmannii and the average heterozygosity value for this population is $13.5 \%$, which falls within the range reported for other cycad species. Fixed allele differences between the species studied was not found at any of the loci studied, which suggest that these species are closely related. DNA sequence analysis of $r b c$ L and ITS $1 \& 2$ genes (1428 and 895 basepairs, respectively) confirmed the close genetic relationships between these taxa. According to ITS and $r b c \mathrm{~L}$ sequences $E$. altensteinii and E. princeps are sibling taxa which form a sister group to E. arenarius, E. horridus, E. latifrons, E. lehmannii, E. longifolius, and E. trispinosus. The genetic distances between both groups were $0.12-0.47 \%$ for ITS and 0.08 $0.16 \%$ for $r b c \mathrm{~L}$ DNA. The results indicate recent (probably pleistocenic) speciation for this group of cycads, and the relationships are discussed with reference to affinities based on morphology and distribution. (C) 2001 Elsevier Science Ltd. All rights reserved.
\end{abstract}

Keywords: Phylogenetic relationships; Encephalartos; Zamiaceae; Allozyme; DNA sequence; rbcL; ITS $1 \& 2$

${ }^{*}$ Corresponding author. Tel.: +27-11-489-2450; fax: + 27-11-489-2286.

E-mail address: fhvdb@na.rau.ac.za (H. van der Bank). 


\section{Introduction}

The taxonomy of the Cycadales is problematic because really distinctive morphological characteristics are lacking in most groups, and species are usually defined in terms of sets of characteristics. Furthermore, the characteristics used for identification may not be of phylogenetic significance due to a high degree of convergence or divergence. It also seems reasonable to assume that at least some of the species in a given geographical area are closely related (i.e. derived from a common ancestor) due to slow reproduction rates (Tang, 1990) and absence of longdistance dispersal mechanisms for seeds. In the Eastern Cape Province of South Africa eight of the 13 known Encephalartos species are thought to be closely related. These are Encephalartos arenarius R.A. Dyer, E. horridus (Jacquin) Lehmann, E. latifrons Lehmann, E. lehmannii Lehmann, E. longifolius (Jacquin) Lehmann, E. princeps R.A. Dyer, and E. trispinosus (Hooker) R.A. Dyer, with E. altensteinii Lehmann thought to be somewhat more distantly related. These are the species used for this study. The remaining species, E. caffer (Thunberg) Lehmann, E. cycadifolius (Jacquin) Lehmann, E. friderici-guilielmi Lehmann, E. ghellinckii Lemaire, and E. villosus Lemaire, most certainly belong to other, more distantly related groups within the genus. The studied species have either or both very strongly dentate (almost dentate-lobed) leaflets and very glaucous leaves (Dyer, 1965a, b). Such dentate leaflets are not known anywhere else in the distribution area of the genus, and glaucous leaves are uncommon elsewhere (Vorster, 1993, 1999). Apart from these two characteristics, these eight species vary greatly in respect of growth form (development of an aerial trunk) and cone morphology. The development of an aerial trunk may well be a rather plastic (albeit at present genetically fixed) reaction to local environmental conditions, as the habitat becomes markedly drier further inland from the coast. The cones, being the reproductive structures, could be expected to provide a more reliable indication of phylogenetic relationships than vegetative characteristics. However, cone morphology varies considerably, and cannot be satisfactorally correlated with vegetative morphological features (Vorster, 1993).

The purpose of this study is to compare the eight species of Encephalartos listed above in respect of DNA sequence (ITS $1 \& 2$ and $r b c \mathrm{~L}$ ) and allozyme data to determine whether they form a phylogenetically coherent group and to determine the relationships between the species. Encephalartos ferox Bertoloni f. is included as outgroup species. We have also analysed a cultivated population of E. lehmannii to compare within- and between species allozymic variation.

\section{Material and methods}

\subsection{Allozyme study}

Electrophoretic data for 126 individuals, from nine species (Table 1), were compared. We used cultivated plants, firstly because of the remote locations of 
Table 1

Locality description of the Encephalartos individuals studied

\begin{tabular}{|c|c|c|c|}
\hline Sample & Species & Locality & Nos. \\
\hline $1-2$ & E. altensteinii & University of Pretoria & 1406,1444 \\
\hline $3-9$ & & KNBG & $\begin{array}{l}\text { Cultivated, AL58-247/16, AL209-69/ } \\
94 \text {, Bathurst, } \\
\text { Mkambati, Boesmans River Mouth, } \\
\text { Grahamstad }\end{array}$ \\
\hline $1-6$ & E. arenarius & GLOW & a \\
\hline $7-8$ & & University of Pretoria & 1429,1464 \\
\hline $9-10$ & & KNBG & 1310/83 AR-2, 1310/83 AR-3 \\
\hline $1-5$ & E. ferox & GLOW & a \\
\hline $1-5$ & & GLOW & a \\
\hline $6-9$ & & University of Pretoria & $1386,1454,1520,1494$ \\
\hline $10-13$ & E. horridus & KNBG & HO-7, HO-10, HO-18, HO-20 \\
\hline 1 & E. latifrons & GLOW & a \\
\hline $2-4$ & & University of Pretoria & $3501,3502,1461$ \\
\hline $5-9$ & & KNBG & $\begin{array}{l}\text { LF-1, LF-2, LF-9, LF-15, 48-13 } \\
\text { directly north of LF-15 }\end{array}$ \\
\hline $1-4$ & E. lehmannii & GLOW & a \\
\hline $5-36$ & & GLOW & b \\
\hline $37-40$ & & University of Pretoria & $1367,1368,1369,1482$ \\
\hline $41-44$ & & Stellenbosch & In Van der Bank et al. (1998) \\
\hline $45-48$ & & KNBG & $\begin{array}{l}\text { 573/82 LH-9, 573/82 LH-7, } \\
\text { Olifantshoek, Christo/Jac }\end{array}$ \\
\hline $1-5$ & E. longifolius & GLOW & a \\
\hline $6-8$ & & University of Pretoria & 1455,1466 , gray type \\
\hline $9-10$ & & KNBG & $574 / 52 \mathrm{LO}-12,53081 \mathrm{LO} 2$ \\
\hline $1-3$ & E. princeps & GLOW & a \\
\hline $4-7$ & & University of Pretoria & $1394,1414,1490,3464$ \\
\hline $8-11$ & & KNBG & $\begin{array}{l}\text { 571/82 PR-18, 571/82 PR-9, } \\
\text { 571/182 TR-8, 571/82 PR-19 }\end{array}$ \\
\hline $1-5$ & E. trispinusus & GLOW & a \\
\hline $6-9$ & & University of Pretoria & $1397,1436,1495,1497$ \\
\hline $10-11$ & & KNBG & 110/83 ТР-41, ТР-38 \\
\hline
\end{tabular}

GLOW, Lowveld National botanical Garden; KNGB, Kirstenbosch National Botanical Gardens.

${ }^{\mathrm{a}}$ Mature plants are not numbered at the GLOW.

${ }^{\mathrm{b}}$ Samples from seedlings.

natural populations, and secondly because plants in nature have become very scarce due to illicit collecting for the ornamental plant trade. We have, however, used only plants of undisputed identity, and with collection data where possible. When sampling different specimens of the same species, we took care not to sample a clone twice. Herbarium voucher specimens of the plants studied were deposited at the herbarium of the Botany Department at the University of Stellenbosch (STEU) and at the herbarium of the Lowveld National Botanical garden (GLOW). Encephalartos ferox was selected as outgroup because it has a number of characteristics not found in the Eastern Cape Province species. It has a soft-textured stem in contrast to the hard and compact stems of the Eastern Cape species: it has salmon-red cones which 
are rare in Encephalartos, the male cones emerge in succession rather than simultaneously and are often borne on markedly long peduncles (a trait of tropical species), and it is geographically far separated from the Eastern Cape (Vorster, 1999).

In order to compare intra- and interspecific variation, we also used seedlings raised from field-collected seed of different plants of E. lehmannii, and grown at GLOW. The seedlings will eventually be planted in one of several gene banks at GLOW.

Leaf tissue extracts were prepared and analysed by starch gel electrophoresis $(12 \%$ gels) using the extraction buffer, standard electrophoretic procedures, method of interpretation of gel banding patterns and locus nomenclature referred to by Van der Bank et al. (1998). The buffers used are: tris-EDTA-borate (A; pH 8.6; Goncharenko et al., 1992); histidine citrate (HC; pH 5.7; Kephart, 1990); trisEDTA-borate (MF; pH 8.6; Markert and Faulhaber, 1965), and lithium-borate (electrode: $\mathrm{pH}$ 8.0) tris-citrate (gel: pH 8.7) (RW; Ridgway et al., 1970). Statistical analysis of allozyme data was executed using BIOSYS-1 (Swofford and Selander, 1981) and DISPAN (Ota, 1993). We have used GENEPOP (Raymond and Rousset, 1995) to determine if significant genotypic differentiation for all species studied could be found.

\subsection{DNA sequence analyses}

Plant material was identical to that used for allozyme analysis; in addition fresh material of E. altensteinii, and E. lehmannii (no. 2) was obtained from the Botanical Garden of Heidelberg University.

DNA was isolated from dried leaves of Encephalartos using the CTAB method (Doyle and Doyle, 1990). The marker genes were amplified by polymerase chain reaction (PCR) using the following primers: $r b c \mathrm{~L}-\mathrm{N}$ (forward) $5^{\prime}$-ATG TCA CCA CAA ACA GAR ACK AAA GC-3'; $r b c$ L-R (reverse) 5'- CAA AAT TAA ATM SGA TCT CTT TCC ATA C-3'; ITS-S10 (forward) 5'-GAA TGA TCC GGT GAA GTG TTC GGA TCG-3'; ITS-AB 102 (reverse) 5'- ACT CTT CCC GGT TCG CTC GCC GTT AC-3'.

\subsubsection{PCR conditions}

A final volume of $50 \mu \mathrm{l}$ contained $0.5-1 \mu \mathrm{g}$ DNA, $5 \mu 110 \times$ Taq buffer $(500 \mathrm{mM}$ $\mathrm{KCl}, 100 \mathrm{mM}$ Tris- $\mathrm{HCl}, 1 \%$ Triton $\times 100, \mathrm{pH} 9.0), 3 \mu 125 \mathrm{mM} \mathrm{MgCl} 2,12.5 \mathrm{pmol}$ primer, $1.5 \mu \mathrm{dNTPs}(10 \mathrm{mM}), 0.75 \mathrm{U}$ Taq-Polymerase (Pharmacia), $1 \mu \mathrm{l}$ DMSO, and $1 \mu 120 \mathrm{mg} / \mathrm{ml} \mathrm{BSA}$. PCR cycle for $r b c \mathrm{~L}: 2 \mathrm{~min}$ at $94^{\circ} \mathrm{C}$, then 30 cycles with $45 \mathrm{~s}$ at $94^{\circ} \mathrm{C}, 90 \mathrm{~s}$ at $45^{\circ} \mathrm{C}$ and $90 \mathrm{~s}$ at $72^{\circ} \mathrm{C}$, and finally $5 \mathrm{~min}$ at $72^{\circ} \mathrm{C}$; ITS: 2 min at $94^{\circ} \mathrm{C}$, then 30 cycles with $45 \mathrm{~s}$ at $94^{\circ} \mathrm{C}, 90 \mathrm{~s}$ at $71^{\circ} \mathrm{C}$ and finally $20 \mathrm{~min}$ at $72^{\circ} \mathrm{C}$.

PCR products were further amplified by Cycle-Sequencing using the "ThermoSequenase fluorescent labelled primer cycle sequencing kit with 7-deazadGTP" (Amersham Life Science) according to the protocol of the manufacturer. Products were sequenced with an automatic sequencer ALFexpress (Pharmacia). Sequences will be deposited with GeneBank. Sequences were aligned manually or with use of CLUSTAL W (1.6) (gap-penalty 10). Aligned sequences were analysed 
using the phylogeny program PAUP* 4.0 (Swofford, 1991). Methods employed were maximum parsimony (MP), neighbour-joining (NJ), and maximum likelihood (MLE). A bootstrap analysis (1000 replicates) was performed to estimate how good the furcations were supported by the data.

\section{Results and discussion}

\subsection{Allozyme study}

Locus abbreviations, enzyme commission numbers, and monomorphic loci are listed in Table 2. Allele products at the following loci were monomorphic: GPI-1, MDH, PGDH, PGM-1, -2, PEPD and PEP-LT1, and those of ACP and PER migrated cathodally. Allele frequencies for polymorphic loci are presented in Table 3, and allozyme phenotypes of putative heterozygotes were congruent with those expected on the basis of the quaternary structure of the enzyme (Ward, 1977).

\subsubsection{Within species variation}

Ellstrand et al. (1990) reported values of $P=50 \%, A=1.61$ and $H=0.08$; Byrne and James (1991) obtained values of $60 \%, 1.8$ and 0.24 ; Sharma et al. (1998b) reported ranges of $P=17.6-35.3 \%, A=1.2-1.4$ and $H=0.02-0.11$; and Sharma et al. (1998a) obtained values of $P=26 \%, A=1.3$ and $H=0.06$. Therefore, the ranges of these values are from 17.6 to $60 \%, 1.2-1.8$ and $0.02-0.11$ respectively. We have obtained an $H$ value of 0.135 , a $P$ value of $35.7 \%$, and an $A$ value of 1.6 for the

Table 2

Locus abbreviations, enzyme commission numbers (E.C. No.) and buffers are listed after each enzyme. See Material and Methods for descriptions of buffers

\begin{tabular}{|c|c|c|c|}
\hline Enzyme & Locus & E.C. no. & Buffer \\
\hline Aspartate aminotransferase & AAT & 2.6.1.1 & A \\
\hline Acid phosphatase & $\mathrm{ACP}$ & 3.1 .3 .2 & $\mathrm{HC}$ \\
\hline Adenylate kinase & AK & 2.7.4.3 & RW \\
\hline Esterase & EST & 3.1.1.- & RW \\
\hline Glucose-6-phosphate isomerase & GPI- $1^{\mathrm{a}},-2$ & 3.5 .1 .9 & MF \\
\hline Leucine aminopeptidase & LAP & 3.4.11.1 & A \\
\hline Malate dehydrogenase & $\mathrm{MDH}^{\mathrm{a}}$ & 1.1.1.37 & $\mathrm{HC}$ \\
\hline Peptidase & & 3.4.-.- & \\
\hline Substrate: Phenylalanyl-proline & PEP-D ${ }^{\mathrm{a}}$ & & RW \\
\hline Leucyl-tyrosine & PEP-LT ${ }^{\mathrm{a}}$ & & RW \\
\hline Peroxidase & PER & 1.11 .1 .7 & MF \\
\hline Phosphoglucomutase & PGM-1 ${ }^{\mathrm{a}},-2^{\mathrm{a}}$ & 5.4 .2 .2 & MF \\
\hline 6-Phosphogluconate dehydrogenase & $\mathrm{PGDH}^{\mathrm{a}}$ & 1.1.1.44 & A \\
\hline
\end{tabular}

\footnotetext{
${ }^{\mathrm{a}}$ Monomorphic loci.
} 
Table 3

Allele frequencies at polymorphic loci for the Encephalartos species studied. See Table 4 for species designations

\begin{tabular}{|c|c|c|c|c|c|c|c|c|c|c|}
\hline \multirow[b]{2}{*}{ Locus allele } & & \multicolumn{9}{|c|}{ Species } \\
\hline & & 1 & 2 & 3 & 4 & 5 & 6 & 7 & 8 & 9 \\
\hline \multirow[t]{2}{*}{ AAT } & A & 1.000 & 1.000 & 1.000 & 1.000 & 1.000 & 1.000 & 1.000 & 0.917 & 1.000 \\
\hline & B & & & & & & & & 0.083 & \\
\hline \multirow[t]{5}{*}{ EST } & A & & & & 0.067 & & & & 0.143 & \\
\hline & B & 1.000 & 0.967 & 0.591 & 0.633 & 0.950 & 0.646 & 0.875 & 0.786 & 0.833 \\
\hline & $\mathrm{C}$ & & 0.033 & 0.364 & 0.200 & 0.050 & 0.293 & 0.125 & 0.071 & 0.167 \\
\hline & D & & & 0.045 & 0.033 & & & & & \\
\hline & E & & & & 0.067 & & 0.061 & & & \\
\hline \multirow[t]{2}{*}{$\mathrm{ACP}$} & A & 1.000 & 0.967 & 0.950 & 0.893 & 0.950 & 0.900 & 0.917 & 0.917 & 0.909 \\
\hline & B & & 0.033 & 0.050 & 0.107 & 0.050 & 0.100 & 0.083 & 0.083 & 0.091 \\
\hline \multirow[t]{3}{*}{ AK } & A & 0.700 & 0.567 & 0.778 & 0.584 & 0.917 & 0.625 & 0.750 & 0.400 & 0.693 \\
\hline & B & 0.300 & 0.433 & 0.222 & 0.333 & 0.083 & 0.208 & 0.250 & 0.600 & 0.269 \\
\hline & $\mathrm{C}$ & & & & 0.083 & & 0.167 & & & 0.038 \\
\hline \multirow[t]{3}{*}{ GPI2 } & A & 1.000 & 1.000 & 1.000 & 0.643 & 0.500 & 0.662 & 0.750 & 0.500 & 0.500 \\
\hline & B & & & & 0.143 & 0.500 & 0.309 & 0.250 & 0.500 & 0.500 \\
\hline & C & & & & 0.214 & & 0.029 & & & \\
\hline \multirow[t]{2}{*}{ LAP } & A & 1.000 & 0.882 & 1.000 & 0.600 & 1.000 & 1.000 & 1.000 & 1.000 & 1.000 \\
\hline & B & & 0.118 & & 0.400 & & & & & \\
\hline \multirow[t]{2}{*}{ PER } & A & 0.500 & 0.125 & 0.188 & 0.071 & & 0.097 & 0.150 & & \\
\hline & B & 0.500 & 0.875 & 0.812 & 0.929 & 1.000 & 0.903 & 0.850 & 1.000 & 1.000 \\
\hline
\end{tabular}

cultivated E. lehmannii population studied. These values fall within the ranges reported above for the $P$ and $A$ values, and it is $2.5 \%$ higher for the $H$ value. The latter value is probably due to the fact that we have studied a cultivated population selected to include the maximum phenotypic variation of the parent plants. Nevertheless, our values are also less than corresponding values reported for other outbreeding plants (Gottlieb, 1981) and for 28 studies of gymnosperms (Hamrick et al., 1979). This is in agreement with the results of the above-mentioned authors on other cycad species.

A zymogram showing more phenotypic variation within than between species in allele products at the EST enzyme coding locus is presented in Fig. 1. Gene diversity analysis revealed that $85 \%$ of the differentiation was intraspecific and only $15 \%$ interspecific. This, together with the fact that the taxa all share the most common allele at all of the enzyme coding loci studied, indicate that they are very closely related and that their divergence must be relatively recent. It also demonstrates that sample error due to small sample sizes is a significant factor to consider. For example, Van der Bank et al. (1998) recommended that the results of their preliminary study should be verified by using larger sample sizes, and it is evident that they have over estimated the amount of genetic differentiation between $E$. altensteinii and E. lehmannii. 


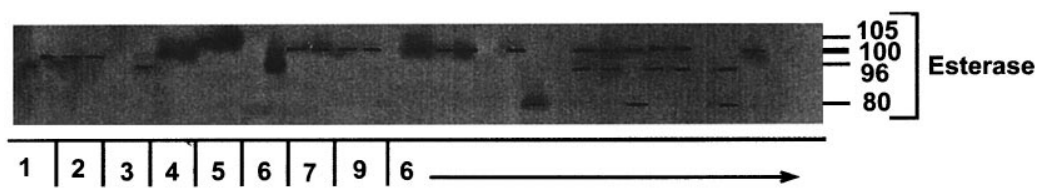

Fig. 1. Zymogram showing allelelic variation in nine cycad taxa and genotypes for individual specimens at the esterase enzyme coding locus.

\subsubsection{Between species differentiation}

The taxonomic uses of allozyme electrophoretic data were reviewed by many authors, including Avise (1974), Thorpe (1982) and Thorpe and Solé-Cava (1994). Several statistically based measures of genetic distance are available to reduce genetic differentiation between populations over a range of enzyme loci to a single figure level. However, the Nei (1978) measure is now used predominantly (Thorpe and Solé-Cava, 1994). It is interesting that the consensus tree has got the same topology as the Nei (1978) tree (Figs. 2e and c).

The Nei (1978) unbiased genetic distance values (adapted for small sample sizes) between taxa are presented in Table 4 . The mean genetic distance values between the ingroup taxa studied are 0.009 and 0.025 between the ingroup and outgroup taxa studied. These values were higher for the other genetic distance values reported in Table 4, but reflect similar groupings, and are included for comparisons with values listed in the literature. Phylogenetic relationships based on all four genetic distance value sets are depicted in Figs. $2 \mathrm{a}-\mathrm{d}$ and a majority-rule consensus tree is shown in Fig. 2e. The cophenetic correlation value for the rooted Wagner trees in Fig. 2a is 95.1\% the chord distance coefficient of (Cavalli-Sforza and Edwards (1967) and 94.9\% for the Rogers (1972) genetic distance (Fig. 2d). Poor bootstrap values (average: 45.4, range: 22-79) between the branches were obtained (using DISPAN), and the only relative good values (65 and 79 in Figs. $2 b$ and c) showed incongruent groupings between these trees. The consensus tree (Fig. 2d) showed that $E$. altensteinii is basal to the other ingroup taxa.

Shaklee et al. (1982), Thorpe (1982) and Thorpe and Solé-Cava (1994) showed the relationship between taxonomic divergence and genetic distance, and concluded that the genetic distance (Nei, 1972) average 0.05 (range: 0.002-0.07) for conspecific populations and 0.30 (range: $0.03-0.61$ ) for congeneric species. The genetic distance values obtained in the present study (Table 4) between the congeneric species $(0.025)$ falls within the lower limit for populations from the same species. The close relationships between the taxa studied is responsible for the low bootstrap values in Fig. 2b (range: 22-65; average: 43) and in Fig 2c (range: 35-79; average: 53). For morphological data, bootstrap values of 50-70 are considered adequate, but for molecular data higher values are required. This supports the results of the DNA analysis, which also indicated that the species are closely related and that recent divergence has occurred.

The Wright (1978) fixation $(F)$ index is another measure to describe differentiation between populations. The amount of differentiation among subpopulations relative to the limiting amount under complete fixation, $F_{S T}$, averaged 0.150 for polymorphic loci (Table 5). This is an indication of little genetic differentiation 
a)
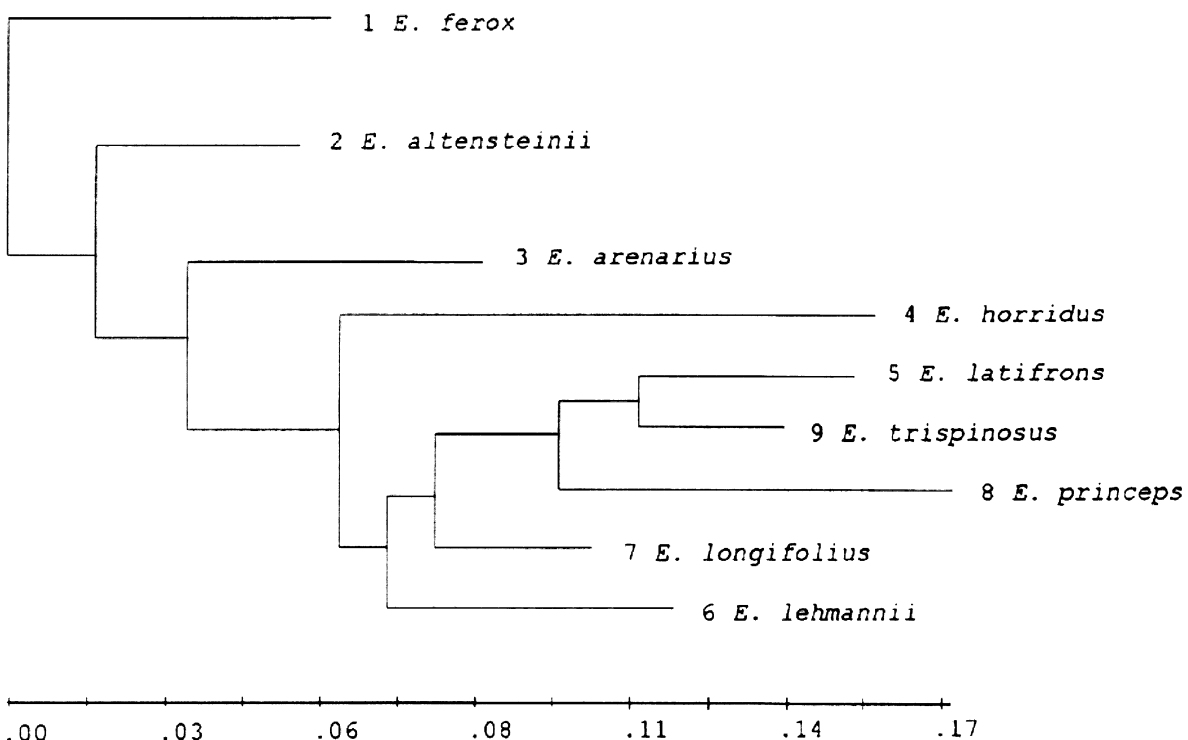

Distance from root

b)

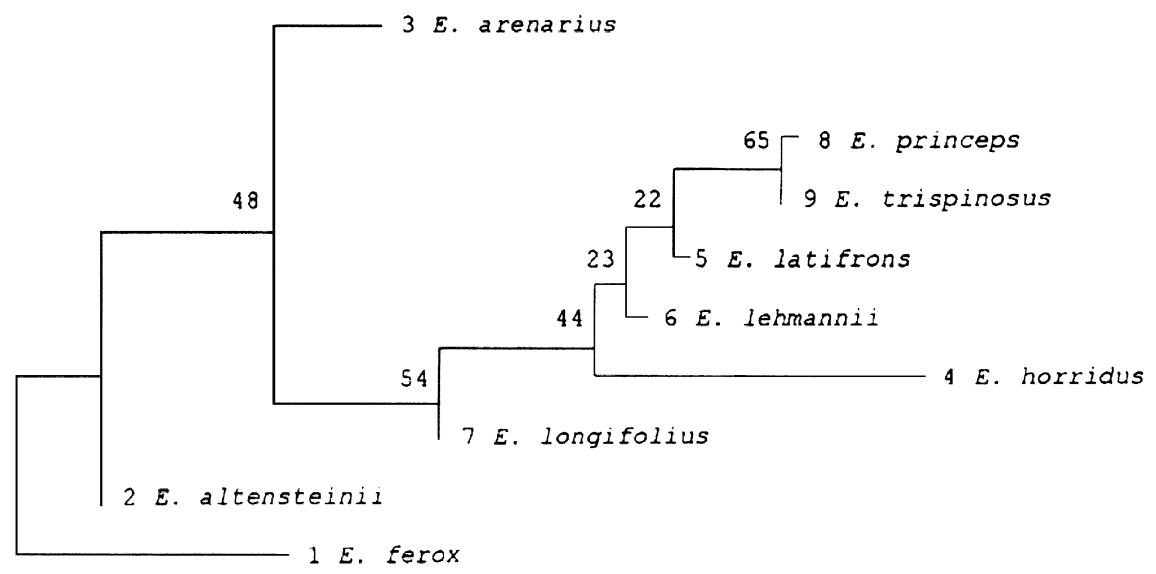

Fig. 2. Dendrograms showing phylogenetic relationships based on the genetic distance values of: (a) Cavalli-Sforza and Edwards (1967) chord distance and the distance Wagner procedure (Farris, 1972), (b) Nei et al. (1983), (c) Nei (1978), (d) Rogers (1972) using the distance Wagner procedure, and (e) a consensus tree based on allozyme data (Table 4) for nine cycad taxa. Numbers at nodes in (b) and (c) are bootstrap values, and majority rule percentages in (e). 
c)

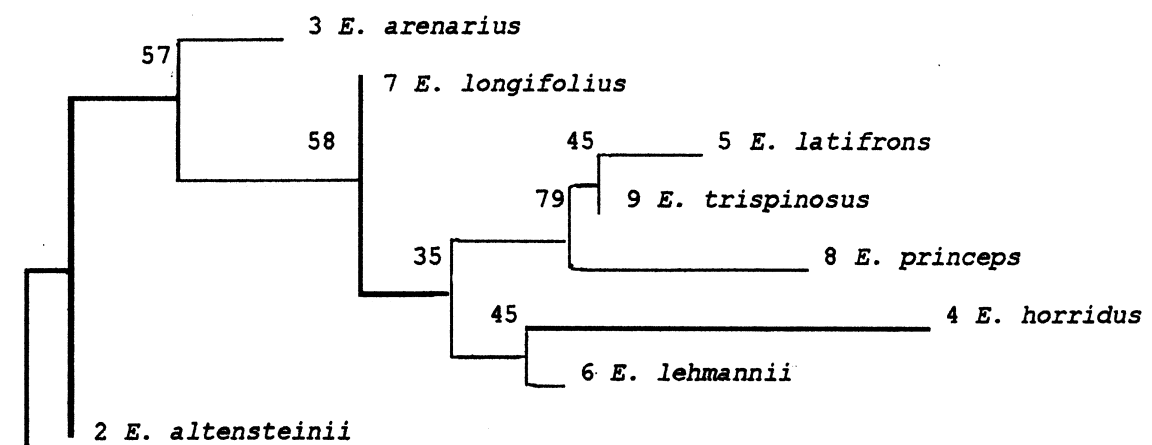

1 E. ferox

d)

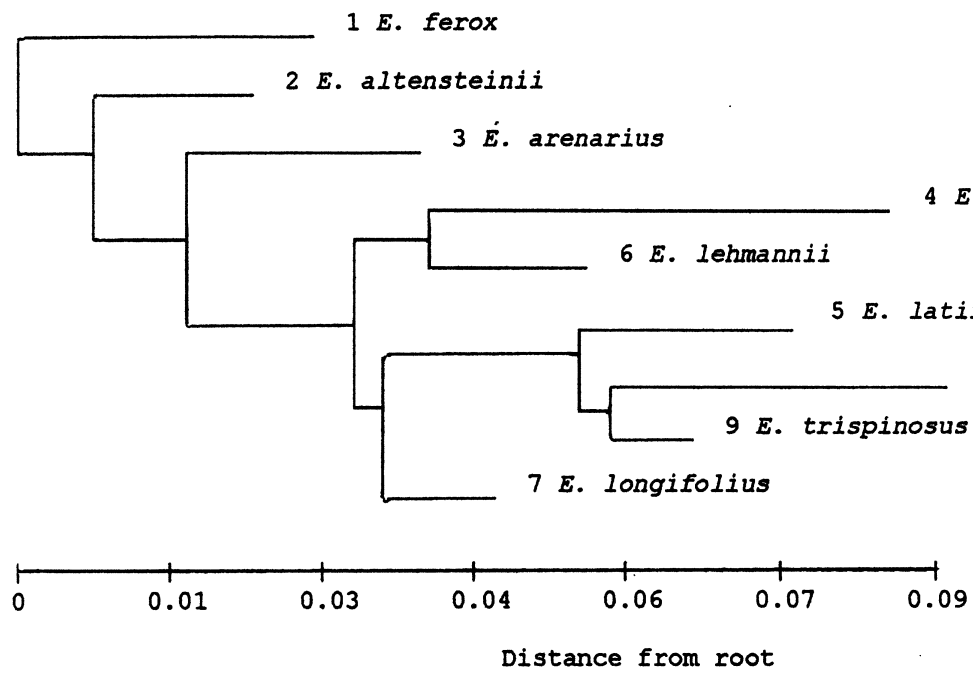

Fig. 2 (continued).

between the cycads studied. The mean value of the Wright (1978) fixation index of individuals relative to the total population, $F_{I S}$, is 0.500 and 0.575 for the total population and its subpopulations $\left(F_{I T}\right)$. The values of $F_{I S}$ are close to zero in most natural populations where random mating within subpopulations occur (Nei, 1986). The $F_{I T}$ value is also indicative of limited barriers to gene flow between the taxa studied. The loci did not contribute much to intraspecific differences $\left(F_{S T}\right.$ values ranged from only 0.09 to 0.295 ) because the taxa shared the most common alleles at all loci (Table 3). Our average $F_{I S}$ value is more than the values reported by other 


\section{e)}

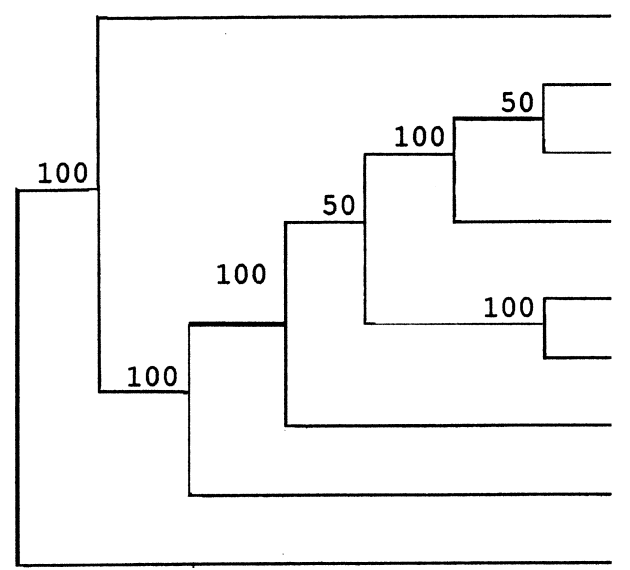

2 E. altensteinii

5 E. latifrons

9 E. trispinosus

8 E. princeps

4 E. horridus

6 E. lehmannii

7 E. longifolius

$3 E$. arenarius

1 E. ferox

Fig. 2 (continued).

researchers for cycads $(0.2-0.47)$. Conversely, the genetic distance values between the taxa in the present study are less than values obtained by other authors for cycads. For example, the Nei (1978) genetic distance values were between 0.014 and 0.250 (Sharma et al., 1998b), from 0.042 to 0.222 for six Encephalartos species (Van der Bank et al., 1998), and the Rogers (1972) genetic distances ranged from 0.023 to 0.072 (Sharma et al., 1998a). Walters and Decker-Walters (1991) also reported similar (low) overall variation in Zamia pumila $\mathrm{L}$. sensu lato and high geographical differentiation. Our maximum genetic distance values were 0.038 between the outgroup species and E. latifrons (Nei, 1978) and 0.118 for the Rogers (1972) genetic distance (Table 4). These values are, therefore, comparable to the values for other cycad taxa, which indicate that the species are closely related.

Even though fixed allele mobility differences between species did not occur at any of the loci studied, significant $(P<0.05)$ differences in allelic distributions were obtained at the following loci: EST (between E. arenarius and E. ferox, E. altensteinii and E. latifrons; E. lehmannii and E. altensteinii, E. latifrons and E. princeps respectively), GPI-2 (between E. horridus and E. altensteinii; and E. altensteinii and E. trispinosus, respectively) and LAP (between E. horridus and all of the other taxa excluding E. altensteinii and E. ferox). In addition, significant $(\mathrm{P}<0.05)$ heterogeneity differences was only found at the ACP locus (Table 6) for the combined analysis of all taxa studied. These differences may present insights into the relationships of the taxa studied.

\subsubsection{Relationships}

Encephalartos altensteinii was included in the study because it occurs in the same geographical area as the others and naturally hybridises with some of them. For example, it interbreeds freely with E. trispinosus where the two species are sympatric 
Table 4

Matrix of Nei's (1978) unbiased genetic distance coefficient below diagonal, Cavalli-Sforza and Edwards' (1967) chord distance above diagonal, and Rogers (1972) and Nei et al. (1983) distances (bold values above and below diagonal, respectively)

\begin{tabular}{lllllllllll}
\hline Species & & 1 & 2 & 3 & 4 & 5 & 6 & 7 & 8 & 9 \\
\hline 1 & E. ferox & $* * * * *$ & 0.106 & 0.135 & 0.223 & 0.198 & 0.191 & 0.135 & 0.219 & 0.207 \\
2 & E. altensteinii & 0.008 & $* * * * *$ & 0.114 & 0.161 & 0.172 & 0.165 & 0.117 & 0.180 & 0.168 \\
3 & E. arenarius & 0.013 & 0.011 & $* * * * *$ & 0.183 & 0.175 & 0.141 & 0.109 & 0.197 & 0.165 \\
4 & E. horridus & 0.035 & 0.014 & 0.018 & $* * * * *$ & 0.195 & 0.143 & 0.170 & 0.189 & 0.175 \\
5 & E. latifrons & 0.038 & 0.029 & 0.029 & 0.027 & $* * * * *$ & 0.130 & 0.093 & 0.130 & 0.066 \\
6 & E. lehmannii & 0.026 & 0.017 & 0.008 & 0.011 & -0.008 & $* * * * *$ & 0.098 & 0.155 & 0.094 \\
7 & E. longifolius & 0.008 & 0.004 & 0.004 & 0.012 & -0.015 & 0.003 & $* * * * *$ & 0.131 & 0.088 \\
8 & E. princeps & 0.036 & 0.015 & 0.028 & 0.014 & -0.008 & 0.005 & 0.004 & $* * * * *$ & 0.107 \\
9 & E. trispinosus & 0.035 & 0.021 & 0.021 & 0.016 & -0.019 & 0.002 & -0.003 & -0.004 & $* * * * *$ \\
1 & & $* * * * *$ & $\mathbf{0 . 0 4 9}$ & $\mathbf{0 . 0 5 9}$ & $\mathbf{0 . 1 1 8}$ & $\mathbf{0 . 0 9 4}$ & $\mathbf{0 . 0 9 3}$ & $\mathbf{0 . 0 6}$ & $\mathbf{0 . 1 1 8}$ & $\mathbf{0 . 0 9 2}$ \\
2 & & $\mathbf{0 . 0 1 4}$ & $* * * * *$ & $\mathbf{0 . 0 5 5}$ & $\mathbf{0 . 0 7 8}$ & $\mathbf{0 . 0 8 0}$ & $\mathbf{0 . 0 7 4}$ & $\mathbf{0 . 0 5 1}$ & $\mathbf{0 . 0 8 6}$ & $\mathbf{0 . 0 7 7}$ \\
3 & & $\mathbf{0 . 0 2 3}$ & $\mathbf{0 . 0 1 6}$ & $* * * * *$ & $\mathbf{0 . 0 8 5}$ & $\mathbf{0 . 0 8 3}$ & $\mathbf{0 . 0 5 1}$ & $\mathbf{0 . 0 4 4}$ & $\mathbf{0 . 1 0 4}$ & $\mathbf{0 . 0 7 3}$ \\
4 & & $\mathbf{0 . 0 6 1}$ & $\mathbf{0 . 0 3 2}$ & $\mathbf{0 . 0 4 1}$ & $* * * * *$ & $\mathbf{0 . 1 0 0}$ & $\mathbf{0 . 0 5 7}$ & $\mathbf{0 . 0 7 3}$ & $\mathbf{0 . 0 9 2}$ & $\mathbf{0 . 0 7 5}$ \\
5 & & $\mathbf{0 . 0 4 8}$ & $\mathbf{0 . 0 3 6}$ & $\mathbf{0 . 0 3 8}$ & $\mathbf{0 . 0 4 7}$ & $* * * * *$ & $\mathbf{0 . 0 6 1}$ & $\mathbf{0 . 0 4 8}$ & $\mathbf{0 . 0 5 6}$ & $\mathbf{0 . 0 2 6}$ \\
6 & & $\mathbf{0 . 0 4 5}$ & $\mathbf{0 . 0 3 4}$ & $\mathbf{0 . 0 2 5}$ & $\mathbf{0 . 0 2 5}$ & $\mathbf{0 . 0 2 1}$ & $* * * * *$ & $\mathbf{0 . 0 3 6}$ & $\mathbf{0 . 0 6 7}$ & $\mathbf{0 . 0 4 0}$ \\
7 & & $\mathbf{0 . 0 2 3}$ & $\mathbf{0 . 0 1 7}$ & $\mathbf{0 . 0 1 5}$ & $\mathbf{0 . 0 3 6}$ & $\mathbf{0 . 0 1 1}$ & $\mathbf{0 . 0 1 2}$ & $* * * * *$ & $\mathbf{0 . 0 6 8}$ & $\mathbf{0 . 0 3 6}$ \\
8 & & $\mathbf{0 . 0 5 9}$ & $\mathbf{0 . 0 4 0}$ & $\mathbf{0 . 0 4 8}$ & $\mathbf{0 . 0 4 4}$ & $\mathbf{0 . 0 2 1}$ & $\mathbf{0 . 0 3 0}$ & $\mathbf{0 . 0 2 1}$ & $* * * * *$ & $\mathbf{0 . 0 3 8}$ \\
9 & & $\mathbf{0 . 0 5 3}$ & $\mathbf{0 . 0 3 5}$ & $\mathbf{0 . 0 3 3}$ & $\mathbf{0 . 0 3 8}$ & $\mathbf{0 . 0 0 5}$ & $\mathbf{0 . 0 1 1}$ & $\mathbf{0 . 0 1 0}$ & $\mathbf{0 . 0 1 4}$ & $* * * * *$ \\
\hline & & & & & & & & &
\end{tabular}

Table 5

Summary of Wright's (1978) F-statistics at all loci

\begin{tabular}{lllr}
\hline Locus & $F_{I S}$ & $F_{I T}$ & $F_{S T}$ \\
\hline AAT & 1.000 & 1.000 & 0.075 \\
EST & 0.241 & 0.330 & 0.117 \\
ACP & 0.327 & 0.339 & 0.018 \\
AK & 0.590 & 0.627 & 0.090 \\
GPI2 & 0.480 & 0.596 & 0.223 \\
LAP & 1.000 & 1.000 & 0.295 \\
PER & 0.593 & 0.674 & 0.198 \\
Mean & 0.500 & 0.575 & 0.150 \\
\hline
\end{tabular}

(Dyer, 1965b; Vorster, 1986). Nevertheless, E. altensteinii differs from the other species in respect of its bright green, narrow, very moderately dentate leaflets, and its yellowish cones, and has been suspected of belonging to a different group of species. Not unexpectedly, in all the phenograms (Fig. 2) it occurs in a basal position.

Encephalartos arenarius closely resembles the other species on account of its short stem, its short and very rigid fronds of which the apices tend to recurve, and its more or less glaucous and very pronounced dentate leaflets. In all the phenograms it is basal to all the remaining ingroup species studied (E. longifolius, E. horridus, E. lehmannii, E. trispinosus, E. latifrons and E. princeps). Vegetatively it very strongly 
Table 6

Contingency Chi-square analysis at polymorphic loci

\begin{tabular}{llccc}
\hline Locus & No. of alleles & Chi-square & D.F. $^{\text {a }}$ & $p$ \\
\hline AAT & 2 & 22.154 & 8 & 0.005 \\
EST & 5 & 64.521 & 32 & 0.001 \\
ACP & 2 & 2.451 & 8 & 0.964 \\
AK & 3 & 29.283 & 16 & 0.022 \\
GP12 & 3 & 41.086 & 16 & 0.001 \\
LAP & 2 & 83.510 & 8 & 0.000 \\
PER & 2 & 21.001 & 8 & 0.007 \\
Total & 2 & 264.007 & 96 & 0.000 \\
\hline
\end{tabular}

${ }^{\mathrm{a}}$ D.F., degrees of freedom.

resembles E. latifrons to such an extent that the two species are not always easy to distinguish in the absence of cones which are distinct in their morphology (Dyer, 1956). In E. arenarius, the female cone scale faces are smooth rather than warty, and the male cone scales have much less prominently produced apices, but as yet we cannot say what the phylogenetic significance of these differences is. It therefore comes as a surprise that these two species are so far apart in all the trees. Very glaucous variants of $E$. arenarius vegetatively also strongly resemble $E$. horridus, and the only obvious difference between the cones is the russet-brown indumentum in E. horridus. It is therefore also unexpected that these two species are so far apart. However, the small genetic distance values and low bootstrap numbers as a result of very similar allele frequencies, indicate that it closely resembles the other species, and that the relationships and variable positions of the other ingroup taxa are probably random.

Encephalartos longifolius is basal to E. princeps, E. trispinosus and E. latifrons in Figs. 2a and d, and basal to E. horridus, E. lehmannii, E. trispinosus, E. latifrons and E. princeps in Figs. $2 \mathrm{~b}$ and $\mathrm{c}$ as well as the consensus tree. All these species have relatively short and very rigid fronds, and typically the very base of the frond has a sharply delineated pale-coloured zone which is also present in E. arenarius. This pale-coloured zone is also present in other species to as far north as Kenya (e.g. E. kisambo Faden and Beentje, 1989), but is usually not nearly as conspicuous as in these Eastern Cape species. However, the separation of E. longifolius is supported by its combination of usually an almost total absence of teeth on the leaflets and welldeveloped arborescent habit. Its basal position relative to E. princeps, E. trispinosus and E. latifrons in Figs. 2a and d corresponds with the drawn-out apices of the microsporophylls and the warty faces of the megasporophylls of all four species, and the very well-developed trunks of E. longifolius, E. latifrons and E. princeps. Of these four species, E. princeps is the only one that habitually produces multiple cones per stem. Encephalartos longifolius hybridises naturally with E. horridus where the two species come into contact near Uitenhage (Vorster, 1986), and where it also hybridises with E. lehmannii in the Paardepoort (JH, personal observation). It is 
possible that hybridisation with E. horridus was previously more extensive, as suggested by occasional specimens exhibiting strongly dentate leaflets.

Encephalartos horridus is vegetatively a very distinctive species. In Fig. 2a, it is basal to E. lehmannii, E. longifolius, E. princeps, E. trispinosus and E. latifrons, and in Fig. $2 b$ it is basal to all these species except E. longifolius. While this is plausible in terms of morphological traits, it is not particularly illuminating. However, in Figs. 2c-e it is grouped together with E. lehmannii. Superficially these two species are morphologically quite different, with the leaflets of E. horridus being heavily pungent-lobed and those of E. lehmannii being almost completely entire at maturity. Nevertheless, there are also close morphological resemblances between the two, including relatively poorly developed stems, hard and strongly glaucous fronds with apices more or less recurving, solitary green cones overlain with russet indumentum, microsporophylls with moderately projecting apices, and megasporophylls with mostly smooth exposed faces. The two species are geographically adjacent, and north of Uitenhage there is a morphologically intermediate population that may or may not be indicative of interbreeding between the two species. Occasional warty female cones in E. horridus may be indicative of past hybridisation with E. longifolius.

Encephalartos lehmannii in all the phenograms is well separated from E. princeps, which it remarkably resembles vegetatively although it differs profoundly in respect of morphology and number of both male and female cones. The two species are also geographically (and thus reproductively) well separated. In all the phenograms it occupies a position close to that of E. horridus.

Encephalartos trispinosus in Figs. 2a-e presents no real conflict with morphological data, falling in the group of species with drawn-out apices of microsporophylls and warty exposed faces of megasporophylls, but nevertheless we are surprised at its wide separation from E. horridus. Vegetatively, these two species can be very similar, both having abbreviated stems and heavily glaucous and lobed fronds. These results confirm that the two species are quite distinct.

Encephalartos latifrons, in all the phenograms, occupies unexpected positions relative to $E$. arenarius and $E$. longifolius. Its cone morphology (see above under $E$. longifolius) supports its grouping with E. trispinosus, E. longifolius, and E. princeps. The surprise is that it lies so far from E. arenarius, which it vegetatively resembles to a marked degree, even though the cones of the two species are quite different. It is also surprising that it lies so far from E. longifolius which it resembles by its thick and long trunk, recurved green leaves, drawn-out microsporophylls, and warty exposed faces of the megasporophylls. Encephalartos longifolius lacks the pungently lobed leaflets of E. latifrons, and occasionally heavily lobed leaflets are suspected to be indicative of past hybridisation with E. horridus.

Encephalartos princeps occupies a position basal to E. trispinosus and E. latifrons in Figs. 2a, c and e. This placement is supported by the similarity of its cone morphology to these species, but not really by its vegetative morphology. Again it is surprising that it lies so far from E. lehmannii which is vegetatively quite similar, although the two species are very different in their cone morphology and geographical distribution. Its vegetative similarity to E. lehmannii may well reflect convergent evolution, because there are conspicuous differences in the number and 
a)

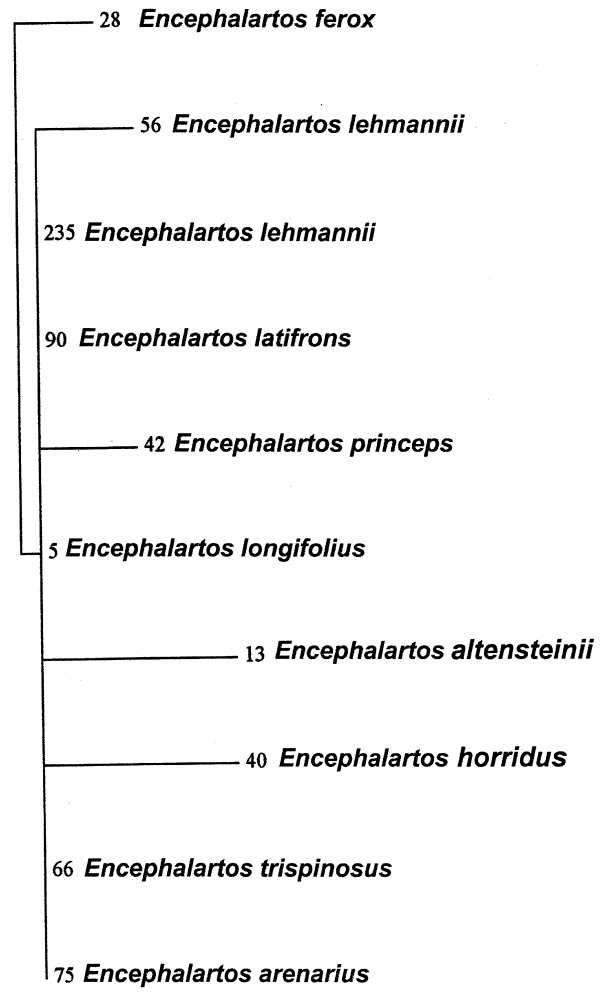

b) Bootstrap

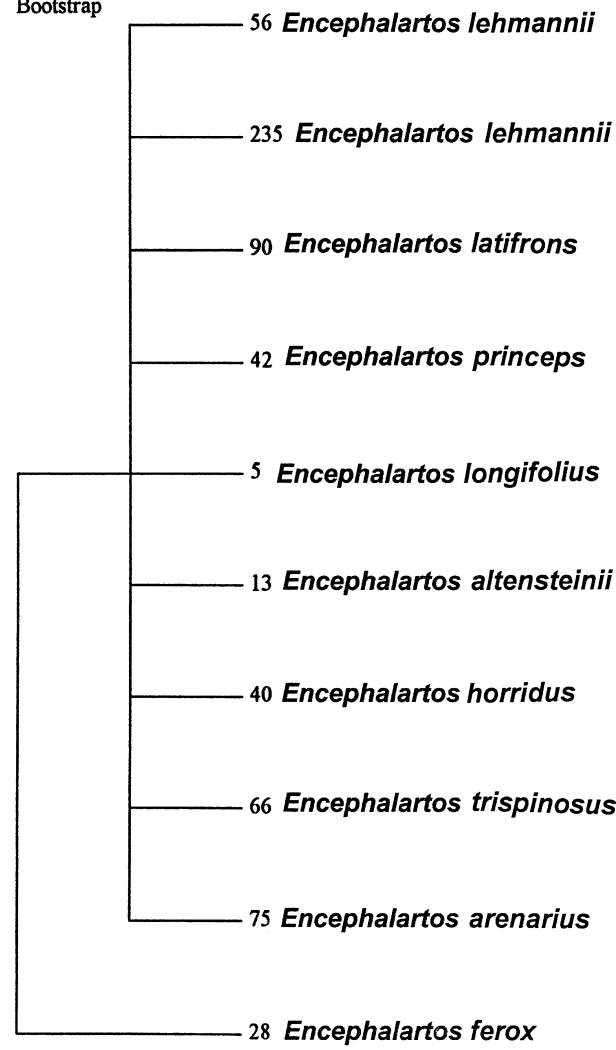

Fig. 3. Molecular phylogeny of Encephalartos inferred from DNA sequences of the $r b c L$ gene and ITS $1 \& 2$ sequences. (a) (b) $=r b c L$ data: (a) MP phylogram; numbers refer to character changes, (b) NJ: bootstrap cladogram; number at bifurcation indicates the occurrence (in \%) of the bifurcation in all trees. MP: $\mathrm{CI}=1.0, \mathrm{RI}=1.0 ;$ (c) (d) = ITS data: (c) MP phylogram of a single most parsimonious tree; numbers refer to character changes, (d) NJ bootstrap cladogram; number at bifurcation indicates the occurrence (in $\%$ ) of the bifurcation in all trees. MP: $\mathrm{CI}=1.0, \mathrm{RI}=1.0$.

morphology of the cones of these two species. Its varying positions in Fig. 2 raises the question of whether its phylogenetic affinities lie at all with the other species. Indeed, it is dissimilar to all the other species studied. It occurs further northwards than any of the other species, its well-developed trunk is more slender compared to the often massive trunks of the others, it has far narrower and softer textured leaflets (like E. lehmannii practically edentate though not pungent), and it habitually bears more than one cone per stem.

\subsection{DNA sequence analyses}

Using E. ferox as outgroup, phylogeny reconstructions from $r b c \mathrm{~L}$ and ITS $1 \& 2$ DNA sequences (Appendix A) produced almost identical tree topologies, 
c)

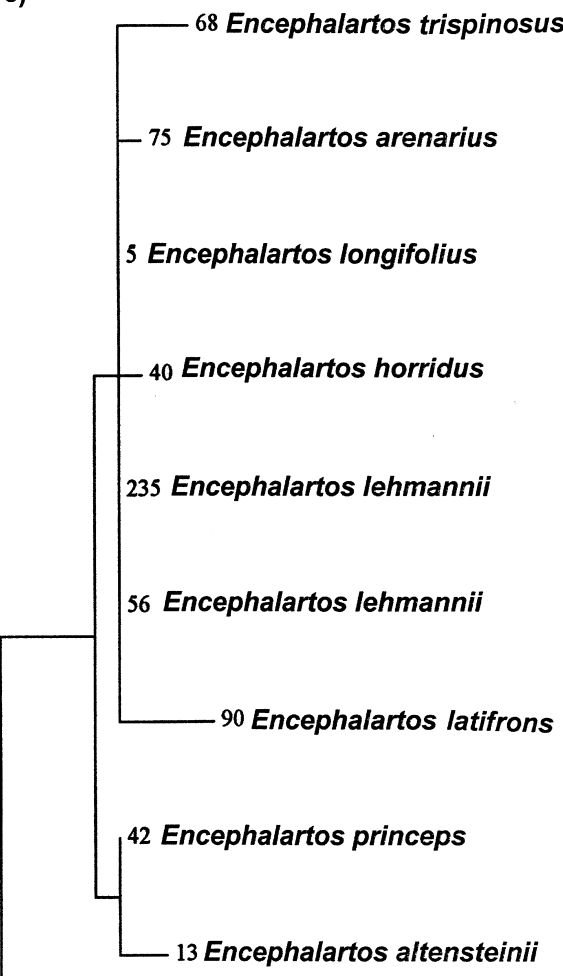

28 Encephalartos ferox d)

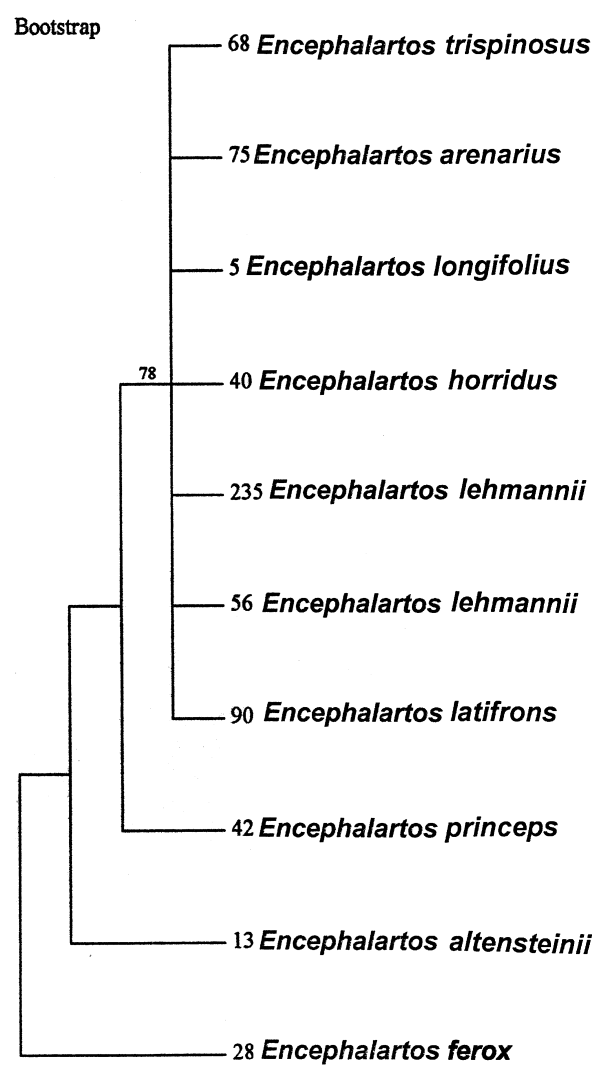

Fig. 3 (continued).

independent of the method employed (MP, NJ or MLE). In Fig. 3, respective phylograms and cladograms for MP (Fig. 3 a, c) and NJ bootstrap (Fig. 3 b, d) trees are illustrated. Because $r b c \mathrm{~L}$ - and nuclear ITS DNA produced similar trees, it indicates that data are not distorted by past hybridisation and reticulate evolution. Two clusters are evident: E. altensteinii and E. princeps cluster together as sibling species, and form a sister group to E. arenarius, E. horridus, E. latifrons, E. lehmannii, $E$. longifolius, and E. trispinosus which show no interspecific sequence variation. A single parsimony-informative character separates both groups of species, and genetic distances (p-distance) between both groups were $0.12-0.47 \%$ for ITS and $0.08-$ $0.16 \%$ for $r b c$ L DNA (Table 7).

The $r b c \mathrm{~L}$ tree resolves into three groups (Fig. 3a). The group comprising $E$. altensteinii is supported by morphological evidence. The group comprising E. princeps is to a far lesser extent supported by morphological evidence, but geographical evidence lends credibility to its separation, presumably reflecting 
Table 7

Uncorrected pairwise distances between taxa; $1.0=100 \%$ divergence. Above diagonal $r b c L$; below diagonal: ITS $1 \& 2$

\begin{tabular}{|c|c|c|c|c|c|c|c|c|c|c|}
\hline \multicolumn{2}{|c|}{ Species } & \multirow{2}{*}{$\frac{1}{-}$} & \multirow{2}{*}{$\frac{2}{0.0016}$} & \multirow{2}{*}{$\frac{3}{0.0024}$} & \multirow{2}{*}{$\begin{array}{l}4 \\
0.0016\end{array}$} & \multirow{2}{*}{$\frac{5}{0.0016}$} & \multirow{2}{*}{$\frac{6}{0.0016}$} & \multirow{2}{*}{$\frac{7}{0.0016}$} & \multirow{2}{*}{$\frac{8}{0.0008}$} & \multirow{2}{*}{$\frac{9}{0.0016}$} \\
\hline & E. ferox & & & & & & & & & \\
\hline & E. altensteinii & 0.0165 & - & 0.0008 & 0.0000 & 0.0000 & 0.0000 & 0.000 & 0.0008 & 0.0000 \\
\hline & E. arenarius & 0.01 & 0.0035 & - & 0.0008 & 08 & & & 016 & 0.0008 \\
\hline & E. horridus & & 0.00 & 0.00 & - & 0.0000 & 0 & .0000 & 0.0008 & 0.0000 \\
\hline & E. latifrol & & 0.0 & 0.0012 & 0.00 & - & 0.0000 & 0.0000 & 0.0008 & 0.0000 \\
\hline & E. leh & & 0.0 & & 0.0000 & 0.00 & - & 0.0000 & 0.0008 & 0.0000 \\
\hline & E. longifolius & 0 & 0.0036 & 0.0000 & 0.0000 & 0.0012 & 0.00 & - & 0.0008 & 0.0000 \\
\hline & E. pri & 0 & 0.0023 & 0.0012 & 0.0012 & 0.0024 & 0.0012 & 0.00 & - & 0.0008 \\
\hline & E. trispinosus & 0.0153 & 0.0035 & 0.0000 & 0.0000 & 0.0012 & 0.0000 & 0.0000 & 0.0012 & - \\
\hline
\end{tabular}

longer genetic isolation than between species of the main group. The third (main) group comprising E. trispinosus, E. arenarius, E. longifolius, E. horridus, E. lehmannii and E. latifrons shows no further resolution, confirming morphological and geographical evidence that these species form a close group, with species equally well defined.

The ITS tree (Fig. 3c) which should provide a better resolution than cpDNA sequences also separates E. altensteinii and E. princeps from the other species. Encephalartos altensteinii and E. latifrons are well defined, as indicated by the relatively long branches on which they are situated, in contrast to E. lehmannii, E. trispinosus, E. horridus, and E. arenarius.

Encephalartos horridus has a fairly wide geographical distribution over which some genetic if not morphological variation could be expected, but plants from different origins had identical DNA sequences. Genetically, the species analysed are closely related. Using $r b c \mathrm{~L}$ data, E. altensteinii and E. princeps show a genetic distance of $0.16-0.08 \%$ to the other Encephalartos species. For $r b c \mathrm{~L}$ data we derived a calibration of $1 \%$ sequence divergence equalling 28 million years (Treutlein, 1998). Using this crude estimate, we can assume that divergence of the species studied started approximately 4-2 million years ago in the Late Pliozene/ Early Pleistocene.

\section{Conclusions}

Encephalartos ferox, selected as outgroup, is not closely related to any of the other species investigated. However, the allozyme and DNA sequence data implicate close and recent evolutionary relationships between the ingroup taxa, and E. altensteinii is separated from the other Eastern Cape species studied by both allozyme and DNA data, as shown by its basal position in all the trees (Figs. 2 and 3).

Encephalartos arenarius, in spite of its very strong vegetative resemblance to E. latifrons, and having rare vegetative characteristics in common with E. horridus 
and E. trispinosus, occupies a basal position relative to E. longifolius, E. horridus, E. lehmannii, E. trispinosus, E. latifrons and E. princeps in all the allozyme phenograms but not in the ITS and rbcL trees. From the allozyme data we conclude that it has the least recent evolutionary links to any of these species, and especially to those that it vegetatively most closely resembles.

Encephalartos longifolius also occupies a basal position in allozyme based trees relative to E. trispinosus, E. latifrons and E. princeps (Fig. 2) with which it shares conspicuously elongated apices to the microsporophylls and warty exposed faces of the megasporophylls.

Encephalartos horridus and E. lehmannii seem to be an offshoot of the previous group, rather than a separate lower branch. These two species are grouped close together in all the phenograms and DNA trees. We conclude that they are closely related, much closer than we previously suspected.

The grouping of E. trispinosus and E. latifrons is surprising. Vegetatively, they are quite different, and the only resemblance to each other is the cone characteristics common to both as well as to E. longifolius and E. princeps. The position of these species in all the phenograms does, however, confirm Dyer's decision to recognise E. arenarius as distinct from E. latifrons (Dyer, 1956), and E. trispinosus as distinct from E. horridus (Dyer, 1965a).

The position of E. princeps as basal to E. trispinosus and E. latifrons in allozyme analyses (Figs. 2a, c and e) agrees with the cone characteristics of these species. The grouping of E. princeps with E. trispinosus in Figs. 2 b and d probably does not reflect its true phylogenetic position, because E. princeps deviates from the general pattern by its multiple cones, geographical distribution, and perhaps its somewhat softertextured foliage. DNA data that places E. princeps as a sister taxon to E. altensteinii conflicts between both data sets.

The genetic distance between these species is much smaller than normal for gymnosperms (Hamrick et al., 1979). The same was found in the Australian genus Macrozamia (Sharma et al., 1998a, b). Possible explanation for the small genetic distances between the species are: (a) these plants are slow to reach reproductive age (it may take 50 years to reach reproductive age under natural conditions; PV personal observation), (b) successful reproductive events are probably separated by a hundred years or more, and (c) the plants lack a mechanism for long distance dispersal of seeds (Norstog and Nicholls, 1997; Tang, 1990; Vorster, 1995). While the small genetic differentiation may cast doubt on the specific status of these presumed species, the separation into species is well supported by morphological and geographical data, and reproductive behaviour, the latter amongst others manifested by different associated (and probably pollinating) insect species (Oberprieler, 1995). It seems certain that the Eastern Cape is an evolutionary centre for Encephalartos (as manifested by the present-day abundance of species and individuals), and has likely been so for an evolutionarily significant time. Traits such as heavily dentate leaflets, glaucous foliage, russet indumentum on the cones, and the tendency to produce single cones per stem, seem to signify that these species are closely related to each other. Our impression is that the present array of species is the result of fairly recent radiation (as manifested by the small and closely spaced distribution areas). 
Evidence of suspected past hybridization comprises phenomena like occasional heavily dentate leaflets in species with normally entire leaflets (like E. longifolius and E. lehmannii), which can only be explained by former different climatic conditions which allowed species to occupy geographical ranges different from the present, allowing them to come into contact with each other. Recent origin of some species is suggested by the polymorphism of for instance E. trispinosus.

The small genetic differences obtained in the present study are indicative of the close relationship between the species. The data confirm that, apart from E. altensteinii, the morphologically similar species (the other ingroup taxa) in the Eastern Cape Province form a phylogenetically closely coherent group. Preliminary DNA amplification fingerprinting (DAF) results (Coetzer et al., unpublished results) indicate a similar grouping of the taxa as reported in Fig. 2e, and it supports the conclusions from the present study (i.e. little differentiation indicating recent speciation).

In conclusion, this is the first attempt at using morphological, allozyme and DNA sequence data to elucidate evolutionary relationships between these species of Encephalartos, and although some meaningful relationships and recent speciation were noticed, it is obvious that much more data are needed before these complex relationships can be clarified satisfactorily.

\section{Acknowledgements}

We would like to thank Susan Myburg from the University of Pretoria and the curator of Kirstenbosch National Botanical Gardens for cycad samples.

\section{Appendix A}

Nucleotide sequences of $r b c L$ (A) and ITS 1\&2 (B) for nine cycad species ("“-" = gap; " "?" = no information obtained) 


\section{(A) $r b c L$ data:}

\section{Encephalartos ferox}

314 Encephalartos altensteinii

75 Encephalartos arenarius

40 Encephalartos horridus

90 Encephalartos latifrons

56 Encephalartos Iehmannii

235 Encephalartos Iehmannit

5 Encephalartos longifolius

42 Encephalartos princeps

66 Encephalartos trispinosus

68 Encephalartos trispinosus

\section{Encephalartos ferox}

314 Encephalartos altensteinii

75 Encephalartos arenarius

40 Encephalartos horridus

90 Encephalartos latifrons

56 Encephalartos lehmannii

235 Encephalartos lehmanni

5 Encephalartos longifolius

42 Encephalartos princeps

66 Encephalartos trispinosus

68 Encephalartos trispinosus
GCACCTGCTGCCCTG???GCAAAG????? :AGCGAACTGTCGAATTCGGTGCTTCGCGGCTGCTGCCGATACCTCGACCA----TCGA????CACATCCGAGCGAATGTCTCGTTAG CACGACGACTTGTCTCTCGATATTCGTTGCGGGGGGTTCG? ?GCAGCGTCGGCGGACC? ?TCTCA??GTTTCG? ?TGTTTGGTG

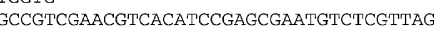
GACGACGACTTGTCTCCGATATTCGTTGCGGGGGTTCGAGGAGCGTCGGCGGACCGGTCTCACCGTTTCGAATGTTTGGTG

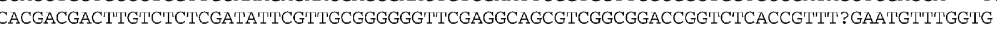
GCACCTGCTG?CCTGGTTGCAAAGACAACGAGCGAACTGTCGAAT??GGTGCTTCGCGGCTG????CGATACCTCGACCA---TCGAACGTCACATCCGAGCGAATGT??CGTTAG CACGACGACTTGTCTCT? ?ATATTCGTTGCGGGGGGTTCGAGGCAGCGTCGGCGGACCGGTCTCACCGTTTCGAATGTTTGGTG ??????????????????:AAGACA??GAGCGAACTGTCGAATTCGGTGCTTCGCGGCTGCTGCCGATACC?CGACCA---TCGAACGTCACATCCGAGCGAATGT?TCGTTAG CACGACGACTTGTCTCTCGATATT?GTTGCGGGG?GTTCGAAGCAGCGTCGGCGGACCGGTCTCACCGTTTCGAATGT?TGG?G ?CACCTGCTGCCCTGGTTGCAAAGACAACGAGCGAACTGTCGAATTCGGTGCTTCGCGGCTGCTGCCGATACCTCGACCA---TCGAACGTCACATCCGAGSGAATGTCTCGTTAG CACGACGACTTGTCTCTCGATATTCGTTGCGGGGGGTTCGAGGCAGCGTCGGCGGACCGGTCTCACCG?TTCGAATGTTTGGTG GCACCTGCTGCCCTGGTTGCAAAGACAACGAGCGAACTGTCGAATTCGGTGCTTCGCGG?TGCTGCCGATACCTCGACCA---TCGAACGTCACATCCGAG? ?AATGTCTCGTTAG CACGACGACTTGTCTCTCGATATTCGTTGCGGGGGGTTCGAGGCAGCGTCGGCGGACCGGTCTCACCGTTTCGAATGTTTGGTG

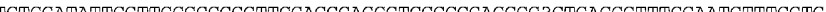
GCACCTGCTGCCCTGGTTGCAAAGACAACGAGCGAACTGTCGAATTC?? ?GC??CGCGGCTGCTGCCGATACCTCGACCA---TCGAACGTCACATCCGAGCGAATGTCTCGNTAG CACGACGACTTGTCTCTCGATATTTCGTTGCGGGGGGTTCGAGGCAGCG?CGGCGGACCGGTCTCACCGTTTTCGAATGTITTGGTG GCACCTGCTGCCCTGGTTGCAAAGACAACGAGCGAACTGTCGAATTCGGTGCTTCGCGGCTGCTGCCGATACCTCGACCA---T? 3 ACGTCACATCCGAGCGAATPTCTCGTTA GCACGACGACTTGTCTCTCGATATTC?TTTGCGGGGGGTTCGAGGCAGCGT?GGCGGACCGGTCTCAC? ?? ?TCGAATGTTTGGTG GCACCTGCTGC?CTGGTTGCAAAGACAACGAGCGAACTGTCGAATTCGGTGCTTCGCGGCTGCTGCCGATACCTCGACC?---TCGAACGTCACATCCGAGCGAATGTCTCGTTAG CACGACGACTTGTCTC?CGATATTCGTTGCGGGGGGTTCGAGGCAGCGTCGGCGGACC?GTCTCACCGTTTCGAATGTTTGGTG

TGTCGGGAATCGGTGCCTCGCCGGGCCTCTGTGTTTCGGCTTCCCACGCGTTCGCT GGGGTGCATCCGGCCCGTTGCACCGTGCCCCT-CCCGCGCGGGGCTTCCGTTTTGACGACCGTCAGCGGAGGCGCGGCGCGTG 作 GGGGTGCATCCGGCCCGTTGCACCGTGCCCCT-CCCGCGCGGGGCTTCCGTTTGGCGACCGTCAGCGGAGGCGCGGCGCGTG

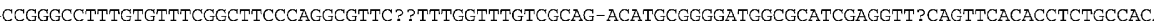
作

CGGGAATCGGTGCCTCGCCGGGCCTTTGTGTTTCGGCTT?CCAGGCGTTCGCTTTGGTTTGTCGC? ?-ACATGCGGGGATGGCGCAT---GGTTCCAGTTCACACCTCTGCCACA GGGGTGCATCCGGCCCGTTGCACCGTGCCCCTTCCCGCGCGGGGCTTCCGTTTGGCGACCGTCAGCGGAGGCGCGGCGCGTG TGTCGGGAAT?GGTGCCTCGCCGGGCCTTTGTGTTTTCGGCTTCCCAGGCGTTCGCTTTGGTTTGTCGCAGCACATGCGGGGATGGCGCATCGAGGTTCCAGTTCACACCTCTGCCACA GGGGTGCATCCGGCCCGTTGCACCGTGCCCCT-CCCGCGCGGGGCTTCCGTTTTGGCGACCGTCAGCGGAGGCGCGGCGCGTG TGTCGGGAATCGGTGCCTCGCCGGGCCTTTGTGTTTCGGCTTCCCAGGCGTTCGCTTTGGTTTTGTCGCAG-ACATGCGGGGATGGCGCATCGAGGTTCCAGTTCACACCTCTGCCACA GGGGTGCATCCGGCCCGTTGCACCGTGCCCCTTCCCGCGCGGGGTTTCGTTTTGGCGACCGTCAGCGGAGGCGCGGCGCGTG TGTCGGGA?TCG?TGCCTCGCCGGGCCTTTGTGTTTCGGCTTCCCAGGCGTTCGCTTTTGGTTTGTCGCAG-ACATGCGGGGATGGCGCATCGAGGTTCCAGTTCACACCTCTGCCACA GGGGTGCATCCGGCCCGTTGCACCGTGCCCCTTCCCGCGCGGGGCTTCCGTTTTGGCGACCGTCAGCGGAGGCGCGGCGCGTG TGTCGGGAATCGTTCCTCGCCGGGCCTTTGTGTTTCGGCTICCCAGGCGTTCGCTTTGGTITGTCGCAG-ACATGCGGGGATGGCGCATCGAGGTTCCAGTTCACACCTCTGCCAC GGGGTGCATCCGGCCCGTTGCACCGTGCCCCTTCCCGCGCGGGGCTTCCGTTTGGCGACCGTCAGCGGAGGCGCGGCGCGTG TGTCGGGAATCGGTGCCTCGCCGGGCCTTTGTGTTTTCGGCTTCCCAGGCGTTCGCTTTGGTTTTGTCGCAG-ACATGCGGGGATCGCGCATCGAGGTTCCAGTTCACACCTCTGCCACA GGGGTGCATCCGGCCCGTTGCACCGTGCCCCT-CCCGCGCGGGGCTTCCGTTTTGGCGACCGTCAGCGGAGGCGCGGCGCGTG

作

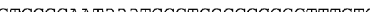
GGGGTGCATCCGGCCCGTTGCACCGTGCCCCTTCCCGCGCGGGGCTTCCGTTTGGCGACCGTCAGCGGAGGCGCGGCGCGTG 


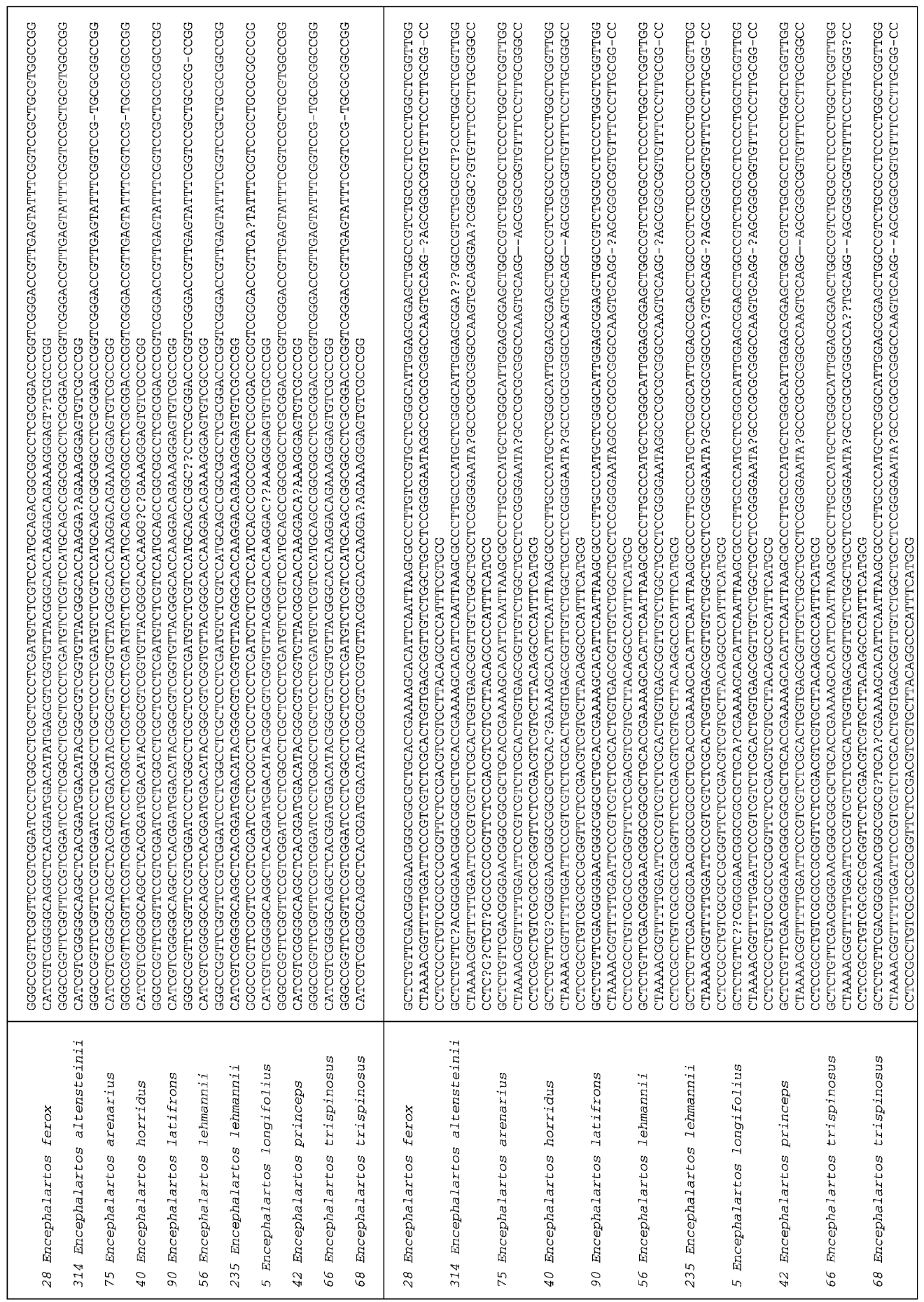




\section{(B) ITS data:}

28 Encephalartos ferox

314 Encephalartos altensteinii

75 Encephalartos arenarius

40 Encephalartos horridus

90 Encephalartos latifrons

56 Encephalartos lehmannii

235 Encephalartos lehmannii

5 Encephalartos longifolius

42 Encephalartos princeps

66 Encephalartos trispinosus

28 Encephalartos ferox

314 Encephalartos altensteinii

75 Encephalartos arenarius

40 Encephalartos horridus

90 Encephalartos latifrons

56 Encephalartos lehmannii

235 Encephalartos lehmannii

5 Encephalartos longifolius

42 Encephalartos princeps

66 Encephalartos trispinosus

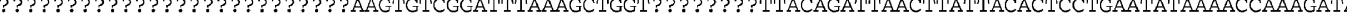
CCGATATCTTGGCAGCGTTCCGAG????TCCCCAACCTGGGGTGCCCGCTGAGGAAGCGGGGGCTGCAGTAGCTGCTGAATCTTCCACTGGTACATGGAC ????????????????????????AAGTGTCGGATTTAAAGCTGGTGTTAAAGATTACAGATTAACTTATTACACTCCTGAATATAAAACCAAAGATA CCGATATCTTGGCAGCGTTCCGAGTAACTCCCCAACCTGGGGTGCCCGCTGAGGAAGCGGGGGCTGCAGTAGCTGCTGAATCTTCCACTGGTACATGGAC ??????????????????????AAGTGTCGGATTTAAAGCTGGTGTTAAAGATTACAGATTAACTTATTACACTCCTGAATATAAAACCAAAGATA CCGATATCTTGGCAGCGTTCCGAGTAACTCCCCAACCTGGGGTGCCCGCTGAGGAAGCGGGGGCTGCAGTAGCTGCTGAATCTTCCACTGGTACATGGAC ???????????????????????AACTCTCGCACC 作 U.

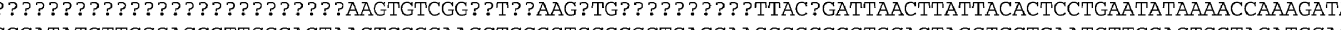
CCGAATCITGCAGCGICCGAGTAACICCCCAACCTGGGGIGCCCGCIGAGGAAGCGGGGCIGCAGTAGCIGCIGAATCIMCCACTGGTACATGGAC  CCGATATCTTGGCAGCGTTCCGAGTAACTCCCCAACCTGGGGTGCCCGCTGAGGAAGCGGGGGCTGCAGTAGCTGCTGAATCTTCCACTGGTACATGGAC ???????????????????????AAGTGTCGGATTTAAAGCTGGTGTTAAAGATTACAGATTAACTTATTACACTCCTGAATATAAAACCAAAGATA CCGATATCTTGGCAGCGTTCCGAGTAACTCCCCAACCTGGGGTGCCCGCTGAGGAAGCGGGGGCTGCAGTAGCTGCTGAATCTTCCACTGGTACATGGAC ????????????????????????:AAGTGTCGGATTTAAAGCTGGTGTTAAAGATTACAGATTAACTTATTACACTCCTGAATATAAAACCAAAGATA CCGATATCTTGGCAGCGTTCCGAGTAACTCCCCAACCTGGGGTGCCCGCTGAGGAAGCGGGGGCTGCAGTAGCTGCTGAATCTTCCACTGGTACATGGAC ?????????????????????????AAGTGTCGGATTTAAAGCTGGTGTTAAAGATTACAGATTAACTTATTACACTCCTGAATATAAAACCAAAGATA CCGATATCTTGGCAGCGTTCCGAGTAACTCCCCAACCTGGGGTGCCCGCTGAGGAAGCGGGGGCTGCAGTAGCTGCTGAATCTTCCACTGGTACATGGAC ?????????????????????????AAGTGTCGGATTTAAAGCTGGTGTTAAAGATTACAGATTAACTTATTACACTCCTGAATATAAAACCAAAGATA CCGATATCTTGGCAGCGTTCCGAGTAACTCCCCAACCTGGGGTGCCCGCTGAGGAAGCGGGGGCTGCAGTAGCTGCTGAATCTTCCACTGGTACATGGAC

?????????????????????????AAGTGTCGGATTTAAAGCTGGT???????TTACAGATTAACTTATTACACTCCTGAATATAAAACCAAAGATA

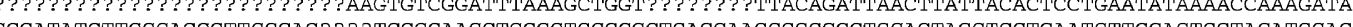
CCGATATCT T. CACTGITI

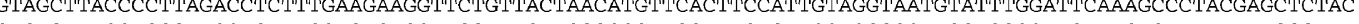
CACTGTTTGGACCGATGGACTIACCAGTCTCGATCGTTACAAGGGGCGATGCTATGACATCGAGCCCGITCCTGGGGAAGAAACTCAATTTATTGCCTAT GTAGCTTACCCCTIAGACCT? ITGAAGAAGGITCTGITACTAACATGITCACTICCATIGTAGGTAATGTATTTGGATTCAAAGCCCTACGAGCTCTAC CACTGTTTGGACCGATGGACTTACCAGTCTCGATCGTTACAAGGGGCGATGCTATGACATCGAGCCCGTTCCTGGGGAAGAAACTCAATTTATTGCCTAT GTAGCTTACCCCTTAGACCTCTTTGAAGAAGGTTCTGTTACTAACATGTTCACTTCCATTGTAGGTAATGTATTTGGATTCAAAGCCCTACGAGCTCTAC CACTGTTTGGACCGATGGACTTACCAGTCTCGATCGTTACAAGGGGCGATGCTATGACATCGAGCCCGTTCCTGGGGAAGAAACTCAATTTATTGCCTAT GTAGCTTACCCCTTAGACCTCTTTGAAGAAGGTTCTGTTACTAACATGTTCACTTCCATTGTAGGTAATGTATTTGGATTCAAAGCCCTACGAGCTCTAC CACTGTTTGGACCGATGGACTTACCAGTCTCGATCGTTACAAGGGGCGATGCTATGACATCGAGCCCGTTCCTGGGGAAGAAACTCAATTTATTGCCTAT GTAGCTTACCCCTTAGACCTCTTTGAAGAAGGTTCTGTTACTAACATGTTCACTTCCATTGTAGGTAATGTATTTGGATTCAAAGCCCTACGAGCTCTAC CACTGTTTGGACCGATGGACTTACCAGTCTCGATCGTTACAAGGGGCGATGCTATGACATCGAGCCCGTTCCTGGGGAAGAAACTCAATTTATTGCCTAT GTAGCTTACCCCTTAGACCTCTTTGAAGAAGGTTCTGTTACTAACATGTTCACTTCCATTGTAGGTAATGTATTTGGATTCAAAGCCCTACGAGCTCTAC CACTGTTTGGACCGATGGACTTACCAGTCTCGATCGTTACAAGGGGCGATGCTATGACATCGAGCCCGTTCCTGGGGAAGAAACTCAATTTATTGCCTAT CACACT CIACCTAC CACTGTTTGGACCGATGGACTTACCAGTCTCGATCGTTACAAGGGCGATGCTATGACATCGAGCCCGTTCCTGGGGAAGAAACTCAATTTATTGCCTAT GTAGCTTACCCCTTAGACCTCTTTGAAGAAGGTTCTGTTACTAACATGTTCACTTCCATTGTAGGTAATGTATTTGGATTCAAAGCCCTACGAGCTCTAC CACTGTTTGGACCGATGGACTTACCAGTCTCGATCGTTACAAGGGGCGATGCTATGACATCGAGCCCGTTCCTGGGGAAGAAACTCAATTTATTGCCTAT GTAGCTTACCCCTTAGACCTCTTTGAAGAAGGTTCTGTTACTAACATGTTCACTTCCATTGTAGGTAATGTATTTGGATTCAAAGCCCTACGAGCTCTAC 


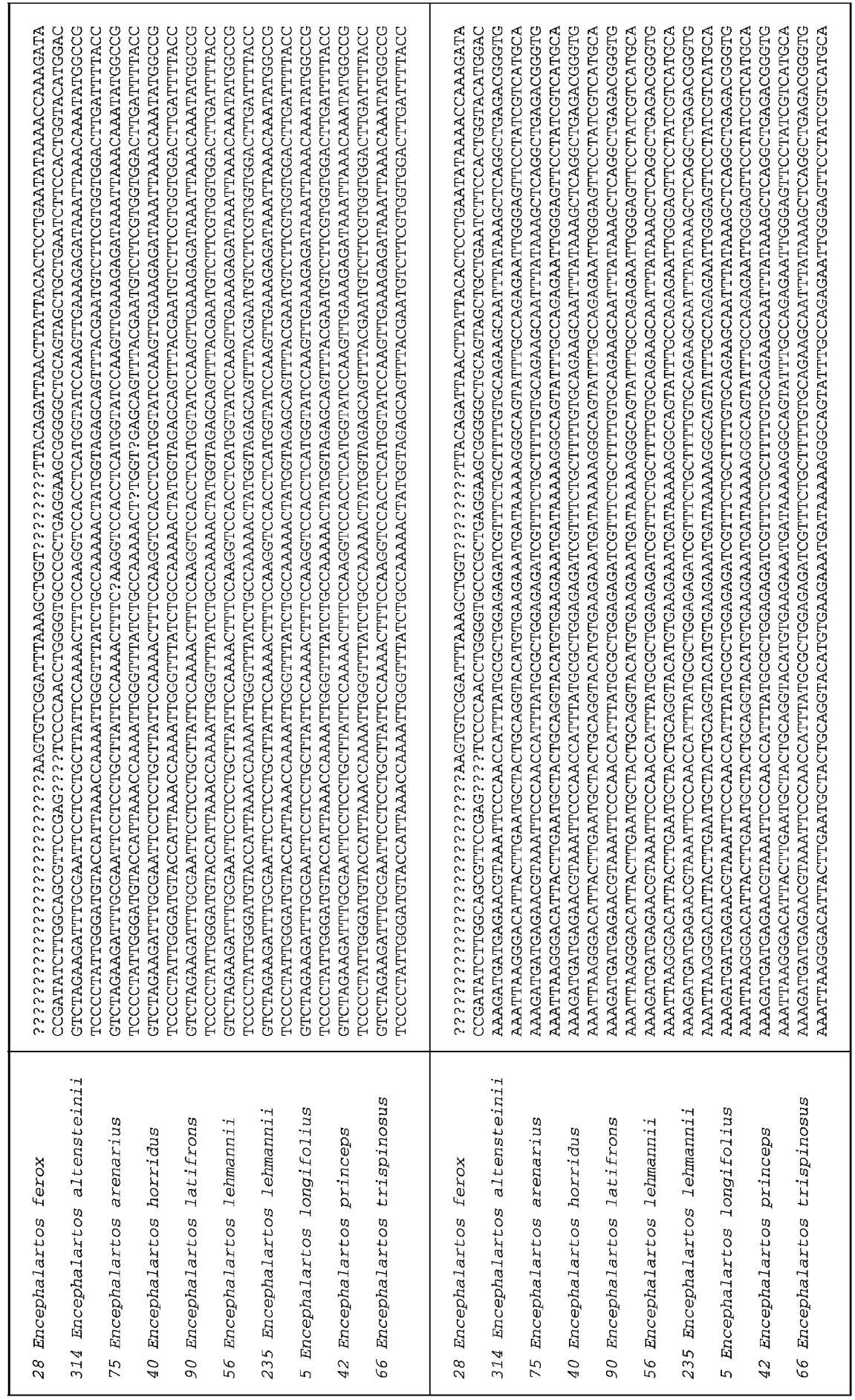




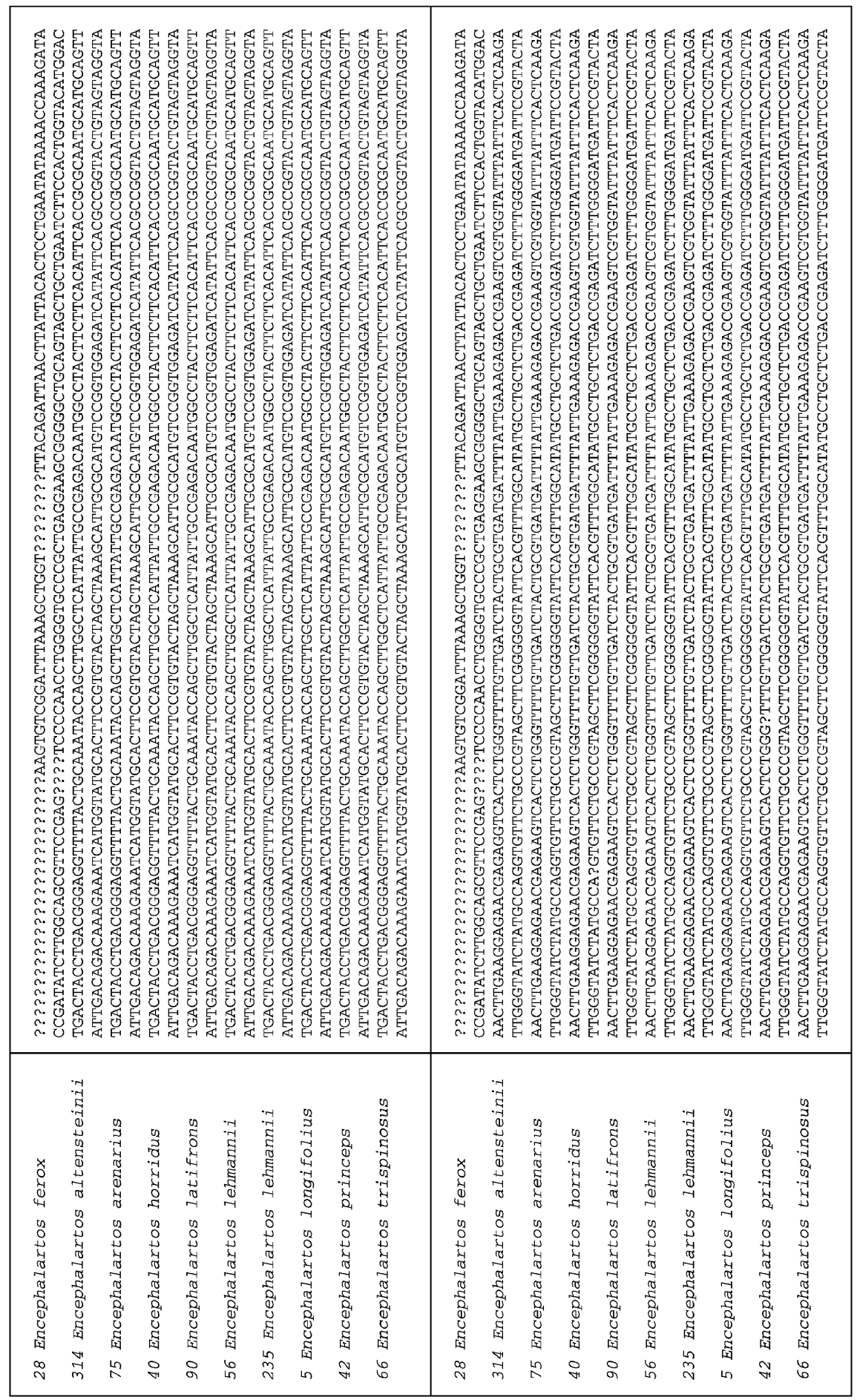




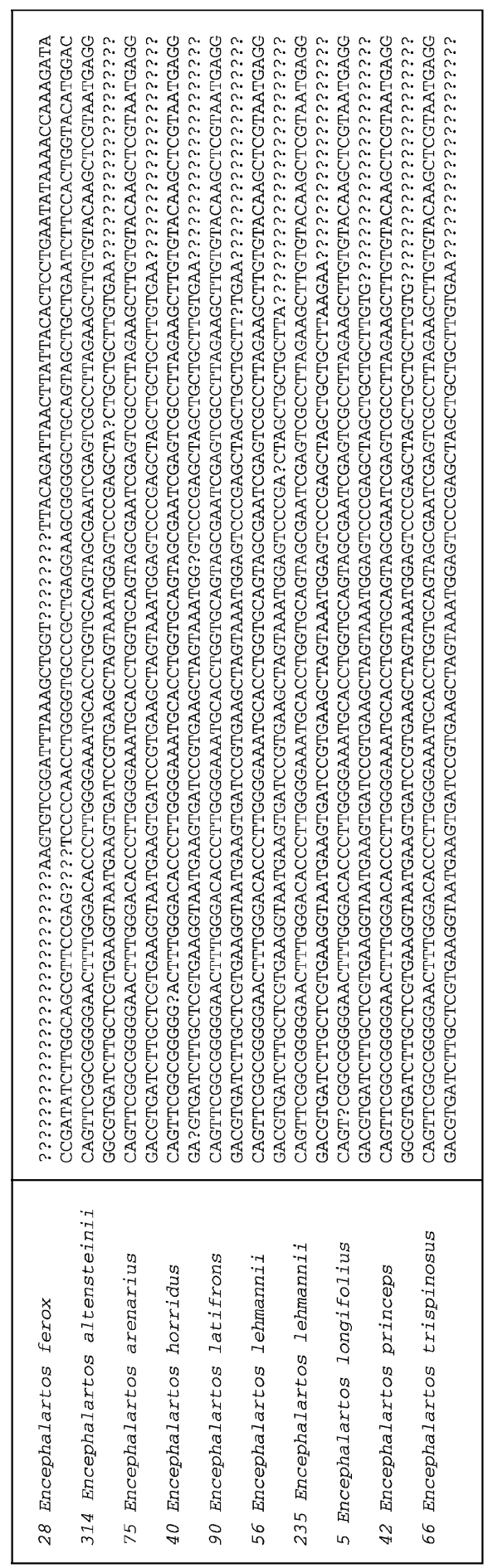




\section{References}

Avise, J.C., 1974. The systematic value of electrophoretic data. Syst. Zool. 23, 465-481.

Byrne, M., James, S.H., 1991. Genetic diversity in the cycad Macrozamia riedlei. Heredity 67, 35-39.

Cavalli-Sforza, L.L., Edwards, A.W.F., 1967. Phylogenetic analysis: models and estimation procedures. Evolution 21, 550-570.

Doyle, J.J., Doyle, J.L., 1990. Isolation of plant DNA from fresh tissue. Focus 12, 13-15.

Dyer, R.A., 1956. A new cycad [Encephalartos arenarius] from the Cape province. J. S. Afr. Bot. 22, 1-4.

Dyer, R.A., 1965a. New species and notes on type specimens of South African Encephalartos. J. S. Afr. Bot. 31, 111-121.

Dyer, R.A., 1965b. The cycads of southern Africa. Bothalia 8, 405-515.

Ellstrand, N.C., Ornduff, R., Clegg, J.M., 1990. Genetic structure of the Australian cycad, Macrozamia communis (Zamiaceae). Amer. J. Bot. 77, 677-681.

Farris, J.S., 1972. Estimating phylogenetic trees from distance matrices. Am. Nat. 106, 645-668.

Goncharenko, G.G., Padutov, V.E., Silin, A.E., 1992. Population structure, gene diversity and differentiation in a natural population of Ceder pines (Pinus subsect. Cembae, Pinaceae) in SSR. Pl. Syst. Evol. 182, 121-134.

Gottlieb, L.D., 1981. Electrophoretic evidence and plant populations. In: Reinhold, L., Harborne, J.B., Swain, T. (Eds.), Progress in Phytochemistry. Pergamon Press, New York, pp. 1-46.

Hamrick, J.L., Mitton, J.B., Linhart, Y.B., 1979. Level of genetic variation in trees: influence of life history characteristics. In: Conke, M.T. (Ed.), Symposium on Isozymes of North American Forest Trees and Forest Insects, USDA Forest General Technical Report, pp. 35-41.

Kephart, S.R., 1990. Starch gel electrophoresis of plant isozymes: a comparative analysis of techniques. Am. J. Bot. 77, 693-712.

Markert, C.L., Faulhaber, I., 1965. Lactate dehydrogenase isozyme patterns of fish. J. Exp. Zool. 159, 319-332.

Nei, M., 1972. Genetic distance between populations. Am. Nat. 106, 283-292.

Nei, M., 1978. Estimation of average heterozygosity and genetic distance from a small number of individuals. Genetics 89, 583-590.

Nei, M., 1986. Definition and estimation of fixation indices. Evolution 40, 643-645.

Nei, M., Tajima, F., Tateno, Y., 1983. Accuracy of estimated phylogenetic trees from molecular data. J. Mol. Evol. 19, 153-170.

Norstog, K.J., Nicholls, T.J., 1997. The biology of the cycads. Ithaca, Cornell University Press.

Oberprieler, R., 1995. The weevils (Coleoptera: Curculionoidea) associated with cycads 1 Classification, relationships, and biology. In: Vorster, P. (Ed.), Proceedings of the Third International Conference on Cycad Biology. Stellenbosch, Cycad Society of South Africa, pp. 295-334.

Ota, T., 1993. DISPAN. Pennsylvania State University, Philadelphia.

Raymond, M., Rousset, F., 1995. GENEPOP (version 1.2): population genetics software for exact tests and ecumenicism. J. Hered. 86, 248-249.

Ridgway, G., Sherburne, S.W., Lewis, R.D., 1970. Polymorphism in the esterases of Atlantic herring. Trans. Amer. Fish. Soc. 99, 147-151.

Rogers, J.S., 1972. Measures of genetic similarity and genetic distance. Studies in Genetics, Univ. Texas Publ. Vol. 7213, pp. 145-153.

Shaklee, J.B., Tamaru, C.S., Waples, R.S., 1982. Speciation and evolution of marine fishes studied by electrophoretic analysis of proteins. Pac. Sci. 36, 141-157.

Sharma, I.K., Jones, D.L., Forster, P.I., Young, A.G., 1998a. Low isozymic differentiation among five species of the Macrozamia heteromera group (Zamiaceae). Biochem. Syst. Ecol. 27, 67-77.

Sharma, I.K., Jones, D.L., Forster, P.I., Young, A.G., 1998b. The extent and structure of genetic variation in the Macrozamia pauli-guilielmi complex (Zamiaceae). Biochem. Syst. Ecol. 26, 45-54.

Swofford, D.L., 1991. PAUP: phylogenetic analysis using parsimony, version 3.1.1. Computer program distributed by the Illinois Natural History Survey. Champaign, IL.

Swofford, D.L., Selander, R.B., 1981. BIOSYS-1: A FORTRAN program for the comprehensive analysis of electrophoretic data in population genetics and systematics. J. Hered. 72, 281-283. 
Tang, W., 1990. Maturity in cycads. Encephalartos 24, 24-26.

Thorpe, J.P., 1982. The molecular clock hypothesis: biochemical evaluation, genetic differentiation and systematics. Annu. Rev. Ecol. Syst. 13, 139-168.

Thorpe, J.P., Solé-Cava, A.M., 1994. The use of allozyme electrophoresis in invertebrate systematics. Zool. Scripta 23, 3-18.

Treutlein, J., 1998. Molekulare Phylogenie der Cycadeen Thesis (Diplom). University Heidelberg, Germany.

Van der Bank, F.H., Vorster, P., Van der Bank, M., 1998. Phylogenetic relationships, based on allozyme data, between six cycad taxa indigenous to South Africa. S. Afr. J. Bot. 64 (3), 182-188.

Vorster, P., 1986. Hybridization in Encephalartos. Excelsa 12, 101-106.

Vorster, P., 1993. Taxonomy of Encephalartos (Zamiaceae): taxonomically useful external characteristics. In: Stevenson, D.W., Norstog, K.J. (Eds.), Proceedings of Cycad 90, the Second International Conference on Cycad Biology. Palm and Cycad Societies of Australia, Australia, Milton, pp. 294-299.

Vorster, P., 1995. Aspects of the reproduction of cycads. 2. An annotated review of known information. In: Vorster, P. (Ed.), Proceedings of the Third International Conference on Cycad Biology. Cycad Society of South Africa, Stellenbosch, pp. 379-389.

Vorster, P., 1999. A review of the arborescent tropical species of Encephalartos. In: Chen, C.J. (Ed.), Proceedings of the Fourth International Conference on Cycad Biology. International Academic Publishers, Beijing, pp. 87-91.

Walters, T.W., Decker-Walters, D.S., 1991. Patterns of allozyme diversity in the West Indies cycad Zamia pumila (Zamiaceae). Am. J. Bot. 78, 436-445.

Ward, R.D., 1977. Relationships between enzyme heterozygosity and quaternary structure. Biochem. Genet. 15, 123-135.

Wright, S., 1978. Evolution and the Genetics of Populations, Vol. 4. Variability Within and Among Natural Populations. University of Chicago, Chicago. 